\title{
Design and Dynamic Equivalent Modeling of Double-Layer Hoop Deployable Antenna
}

\author{
Hongwei Guo, ${ }^{1}$ Chuang Shi $\mathbb{D}^{1},{ }^{1}$ Meng Li, ${ }^{2}$ Zongquan Deng, ${ }^{1}$ and Rongqiang Liu $\mathbb{D}^{1}$ \\ ${ }^{1}$ State Key Laboratory of Robotics and System, Harbin Institute of Technology, Harbin, Heilongjiang, China \\ ${ }^{2}$ Qian Xuesen Laboratory of Space Technology, China Academy of Space Technology, Beijing, China \\ Correspondence should be addressed to Chuang Shi; ty12shichuang@126.com and Rongqiang Liu; liurq@hit.edu.cn
}

Received 1 August 2017; Revised 20 November 2017; Accepted 6 December 2017; Published 28 January 2018

Academic Editor: Paolo Tortora

Copyright (C) 2018 Hongwei Guo et al. This is an open access article distributed under the Creative Commons Attribution License, which permits unrestricted use, distribution, and reproduction in any medium, provided the original work is properly cited.

\begin{abstract}
This study proposes deployable units driven by elastic hinges and a double-layer hoop deployable antenna composed of these units. A rational modeling method based on the energy equivalence principle is presented to develop an equivalent model of the doublelayer hoop antenna in accordance with the structural characteristics of the antenna. The equivalent beam models of the rods with elastic hinges are proposed. The relationship of geometrical and material parameters is established considering the strain energy and the kinetic energy of the periodic unit, which are the same as those of the equivalent beam in the same displacement field. The equivalent model of the antenna is obtained by assembling several equivalent beam models in the circumferential direction. The precision of the equivalent model of the antenna is acceptable as found by comparing the modal analysis results obtained through equivalent model calculation, finite element simulation, and modal test.
\end{abstract}

\section{Introduction}

The development of the aerospace industry leads to the requirement of increasingly large and light antennas to meet the needs of space missions [1]. The transport rockets used at present possess limited storage space; thus, large antennas must be designed as deployable mechanisms that can be folded into a compact configuration before launch and be deployed into a predetermined shape in the orbit [2]. Many types of antenna have been constructed. You and Chen [3-6] and Huang et al. [7] developed deployable mechanical networks using Bennett, Myard, and Bricard linkages. Lu et al. [8] constructed a deployable mechanical network based on Surrus linkages and scissor joints. The hoop truss deployable antenna is an ideal structural form for large-aperture antenna due to its high folding ratio and small mass, which enable it to keep a stable mass and avoid radical mass fluctuation when its diameter is increasing [9]. The United States [10] launched a single-layer hoop deployable antenna with a diameter of $12.25 \mathrm{~m}$ in 2000 . The Pactruss deployable antenna, which is composed of inner deployable truss, outer deployable truss, and central scissor-type link mechanism, was proposed by Escrig [11]. In 2012, Datashvili $[12,13]$ developed a new double-hoop deployable truss and conducted a test for its deployable function. You et al. [14] proposed a hoop mechanism with double-layer scissor hinge. Yan et al. [15-17] proposed a new configuration of a doublelayer deployable antenna mechanism and studied the dynamic characteristics of its deployment process. Qi et al. $[18,19]$ proposed a large deployable mechanism based on plane-symmetric Bricard linkage and a novel large ring deployable mechanism based on a six-bar linkage unit. However, when the antenna diameter is expanded to $100 \mathrm{~m}$ or more, the existing structure form cannot meet the required stiffness to work normally, and the driving system of the antenna is extremely complex. As a result, a new doublelayer hoop deployable antenna with high stiffness, lightweight, and passive driver should be introduced.

The dynamic characteristics of a large deployable antenna greatly influence its position and posture, which are important parameters in the structural design. Many scholars have studied this field and achieved significant progress. Li [20] established a multi-rigid-body dynamic model of a hoop truss antenna. Neto et al. [21] studied the dynamic 
coupling characteristics of flexible satellites based on the theory of flexible multibody. Zhang et al. [22] constructed a flexible multibody dynamic model of a flexible deployable antenna. However, the dynamic models established using such methods still present many degrees of freedom. This characteristic contradicts with the low-order dynamic models required by the structural vibration control. The equivalent model can provide great convenience for solving the effects of structural and material parameters and the dynamic characteristics of structures. The establishment of an equivalent model that cannot only reflect the dynamic characteristics of the structure but also possess lower orders becoming a key problem for the large deployable antenna [23]. Noor et al. [24-27] set up an equivalent continuum model of linear-type space truss composed of triangular cross-sectional periodic unit. Salehian and Inman $[28,29]$ constructed a continuum model of the linear plane truss, and the results of the dynamic analysis were verified by experiments. Bruls et al. [30] proposed a method for global modal parameter reduction of a multiflexible body system. Naets et al. [31-33] applied a reduced-order control model of the multiflexible body system established using this method to the hardware in the loop real-time control. Liu et al. investigated the dynamic equivalent modeling of the components of most antenna mechanisms, which provided important references for the dynamic study of large deployable antenna mechanisms. They established an equivalent dynamic model for hoop truss structure composed of planar repeating elements $[34,35]$, an equivalent circular ring model for radial vibration analysis of hoop truss structures [36], an equivalent dynamic model for the inflatable parabolic membrane reflector [37], and an equivalent dynamic model for the cable net of the antenna reflector [38]. Although much literature is available on the establishment of the equivalent continuum model of the linear truss structure and the plane truss, inconsiderable work has been published on the establishment of the equivalent model of the double-layer hoop antenna. The double-layer hoop antenna is composed of multiple structures with the same repeating threedimensional truss unit and can thus use the continuum equivalent modeling method mentioned above.

In accordance with the requirement of a large antenna, this study proposes deployable units driven by elastic hinges and a double-layer hoop deployable antenna composed of these units. The equivalent model is obtained on the basis of the principle of energy equivalence to describe the dynamic characteristics of the double-layer antenna. The validity of the equivalent model is verified by comparing with the results of the finite element method and the modal test data.

The remainder of the paper is organized as follows. In Section 2, the double-layer hoop deployable antenna is presented. In Section 3, a method for constructing the equivalent model is proposed and the equivalent beam models of the rods with elastic hinges are deduced. In Section 4, the strain energy and kinetic energy of the unit are studied. In Section 5 , the strain energy and kinetic energy of the beam model are calculated. Subsequently, the equivalent model based on the energy equivalence principle is established. In Section 6,

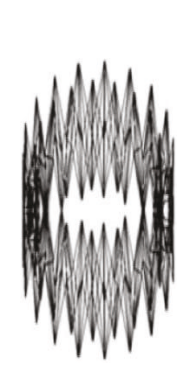

(a) Folded state

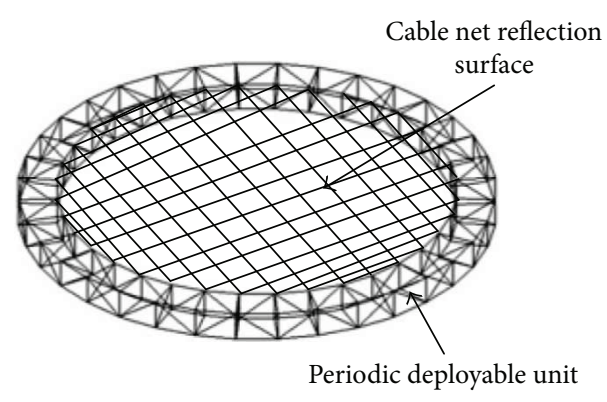

(b) Expanded state
Figure 1: Composition of the double-layer hoop antenna.

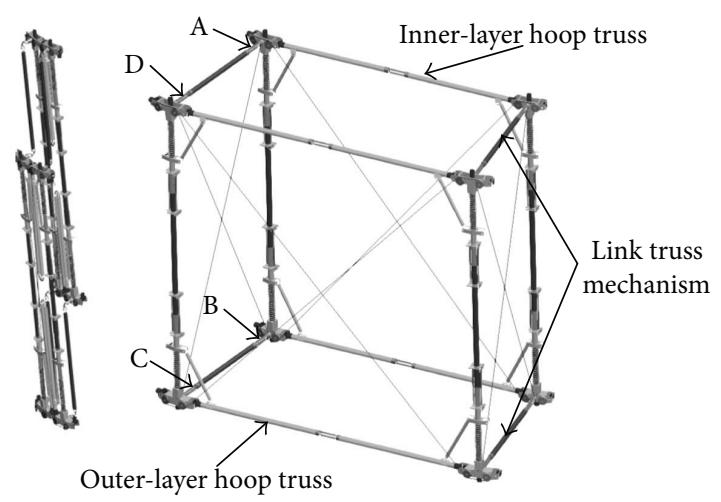

Figure 2: Periodic deployable unit.

the validity of the equivalent model is analyzed. Conclusions are drawn in the last section of the paper.

\section{Double-Layer Hoop Deployable Antenna Mechanism}

The stiffness of a single-layer hoop deployable antenna cannot meet the rigidity requirements of the truss mechanism when the diameter increases to a certain extent, whereas the stiffness of a double-layer hoop deployable antenna has a larger increase and can meet the demand of a largediameter deployable antenna.

As shown in Figure 1, a double-layer hoop antenna is composed of a periodic deployable unit and cable net reflection surface. A periodic deployable unit driven by elastic hinges for meeting the requirements of high stiffness and low mass is presented in Figure 2.

The deployment process of the unit is divided into two stages. First, the inner and outer ring trusses are deployed in the circumferential direction. Second, the inner and outer ring trusses are deployed in the radial direction under the action of the link truss mechanism. Figures 2 and 3 indicate that the rotation joints of link truss mechanisms $\mathrm{A}, \mathrm{B}, \mathrm{C}$, and $\mathrm{D}$ are connected with elastic hinges. When the antenna is folded, the elastic hinge uses its stored elastic potential energy to promote the unit to deploy. When the antenna is fully deployed, the upper and lower chords are locked due to the self-locking characteristic of 


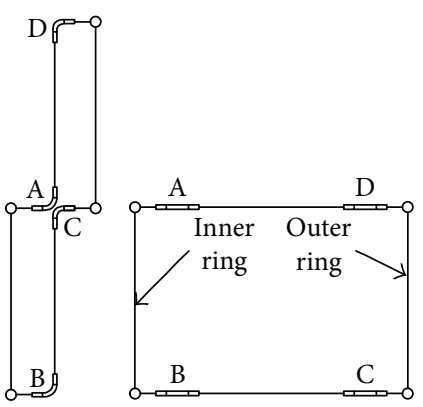

FIGURE 3: Link truss unit.

the elastic hinge. The locking of the entire mechanism is finally completed.

The inner and outer ring truss mechanisms are slidercrank-type unit driven by elastic hinges, as shown in Figure 4 . The basic unit is composed of two vertical supporting rods, four chords, and two elastic hinges. Rotation joints $\mathrm{A}, \mathrm{B}, \mathrm{C}$, and D are connected with elastic hinges. The two cranks are fixed at two adjacent cross bars, and the sliding block is sheathed on the vertical pole. Two speed control cables are installed in the cross state. One end of the cable is connected with the displacement compensation spring. The other end is connected with the drive motor. When the entire mechanism is in its folded state, the elastic hinges are in a compressed state. After the lock is released, the sliding block will slide on the vertical rod under the driving moment of the elastic hinges. The turning angles of the two cranks are equal in the movement process under the action of the slider-crank mechanism, thereby realizing the synchronous deployment of the adjacent units. The impact collision can be avoided through controlling the release rate of the two speed control cables, and then, the entire mechanism can be deployed smoothly. After the entire mechanism is deployed, the rope displacement is compensated by the rope displacement compensation spring to prevent the rope from slack.

As shown in Figure 5, the elastic hinge is a component with stable structural and drive functions. One elastic hinge is composed of two hinge joints, two pieces of elastic reed, and four reed clamps.

The material of elastic hinges is titanium-nickel alloy Ni36CrTiAl with a mass density of $\rho=8.0 \times 103 \mathrm{~kg} / \mathrm{m} 3$, Poisson's ratio $v=0.35$, and Young's modulus $E=36.94 \mathrm{GPa}$ [39]. This material has high strength, high elastic modulus, high elasticity, and good corrosion resistance. It is an ideal material for making elastic hinges.

The elastic potential energy is stored in the elastic hinge to provide the drive torque in its folded state. Relevant research has indicated that the performance of the torque characteristics of the elastic hinge is strong nonlinear and a great peak torque exists in its fully expanded state during the movement from the folded state to the expanded state. Therefore, the elastic hinge exhibits the characteristics of the beam with high bending stiffness in its expanded state. Given its lightweight, small size, and other advantages, the elastic hinge can replace the traditional spring-driven hinge.

\section{Equivalent Model Modeling Method and Process}

The equivalent continuum model has the following advantages. First, the model can be used to evaluate the overall performance of the double-layer hoop antenna. Second, the characteristics of the antenna composed of different unit structures are easy to compare and analyze using the model. Third, the model can be adopted to evaluate the effects of the structural and material parameters of the antenna. Finally, the analytical solution of the dynamic characteristics of the antenna can be obtained using the equivalent model. The model will provide great convenience for solving the antenna subjected to static, thermal, and dynamic loads. In this study, a rational modeling method based on the energy equivalence principle is proposed to develop an equivalent continuum model of the double-layer hoop periodic deployable unit.

The bending and torsional stiffness of the inner and outer layers and the link truss that contains the elastic hinge in $x, y$, and $z$ directions are calculated using the finite element software to simulate their real stress condition. The equivalent beam models of the rods can be instituted by substituting the calculation results into the parameters of the beam element.

The details of the modeling process of the equivalent model of the unit are depicted in Figure 6. First, a basic periodic unit is separated from the repeated units composed of a double-layer hoop deployable antenna. Second, the nodal displacement of any point and the element strain in the periodic unit are then expressed through the displacement and strain components at the center of the periodic unit in accordance with the kinematical assumptions. Third, the strain and kinetic energies of unit components are calculated. Fourth, the strain and kinetic energies in terms of nodal displacement, geometrical structure, and material parameters of the unit and the continuum model are derived. Subsequently, the equivalent stiffness matrix and mass matrix of the equivalent continuum model are obtained based on the energy equivalence principle. Finally, the equivalent models of the unit and the entire antenna are developed.

The equivalent beam model of the unit is shown in Figure 7. The equivalent model of the entire antenna can be obtained by assembling several equivalent beam models in accordance with the geometric topology of the original structure.

\section{Calculation of the Unit Energy}

4.1. Kinematic Assumptions and Displacement Expansions. As shown in Figure 7, a basic periodic unit is separated from the repeated units composed of the double-layer hoop deployable antenna. The Cartesian coordinate system based on the right-hand rule is established, and its origin is located at the unit center. The deformed positions of any cross section of each unit shown in Figure 7 are defined by 12 displacement parameters. Therefore, the displacements in the plane of the cross section are assumed to be specified by a total of 12 parameters. The displacement components $u, v$, and $w$ are assumed to have a linear variation along the $x$-axis 

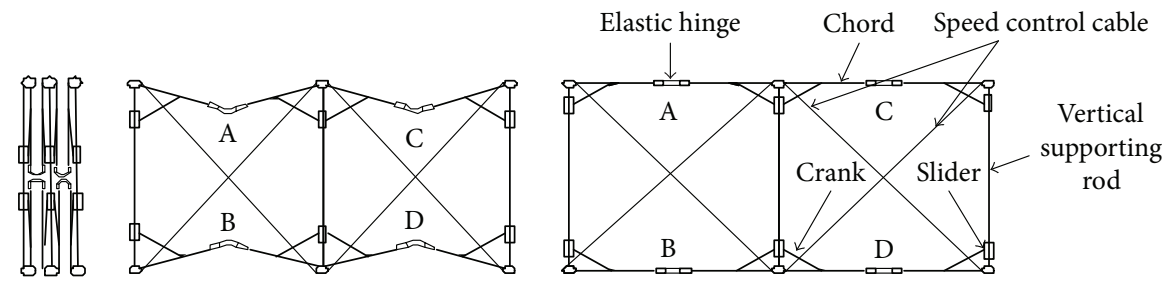

FIgURE 4: Slider-crank mechanism unit.

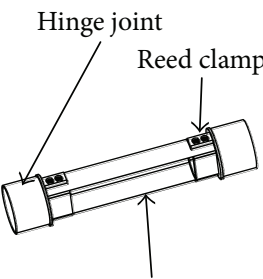

Elastic reed

(a) Schematic diagram of the structure

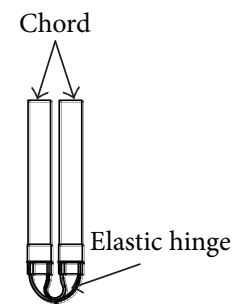

(b) Folded state

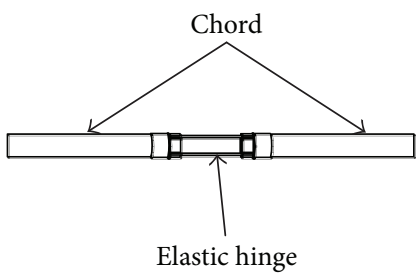

(c) Expanded state

FIgUre 5: Elastic hinge.

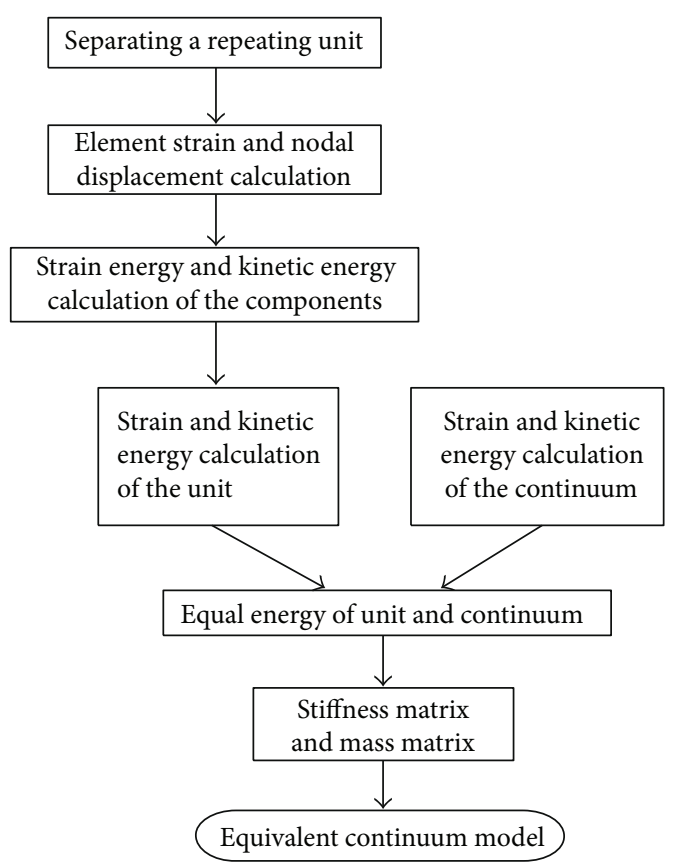

FIgURE 6: Modeling flow chart.

in the plane of the cross section (planes $y-z$ ). The displacement field in the cross-sectional plane can be expressed as follows:

$$
\begin{aligned}
& u(x, y, z)=u^{0}-y \phi_{z}+z \phi_{y}+y z \bar{u} \\
& v(x, y, z)=v^{0}+y \varepsilon_{y}{ }^{0}+z\left(-\phi_{x}+\frac{1}{2} \gamma_{y z}{ }^{0}\right)+y z \bar{v} \\
& w(x, y, z)=w^{0}+z \varepsilon_{z}{ }^{0}+y\left(\phi_{x}+\frac{1}{2} \gamma_{y z}{ }^{0}\right)+y z \bar{w}
\end{aligned}
$$

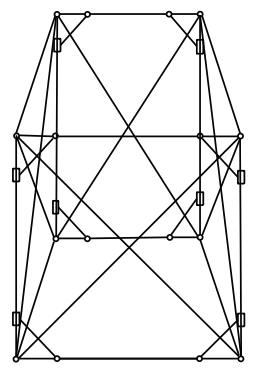

Double-layer hoop periodic unit

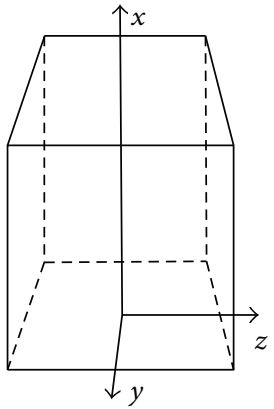

Equivalent continuum beam model

FIGURE 7: Equivalent process.

where $u^{0}, v^{0}$, and $w^{0}$ are the nodal displacement components at $y=z=0 ; \phi_{x}, \phi_{y}$, and $\phi_{z}$ are the rotation components; $\varepsilon_{y}{ }^{0}$ and $\varepsilon_{z}{ }^{0}$ are the principal strains in the $y$ and $z$ directions, respectively; $\gamma_{y_{z}}{ }^{0}$ is the shearing strain in the plane of the cross section (plane $y-z$ ); and $\bar{u}, \bar{v}$, and $\bar{w}$ are the warping and distortion of the cross section (plane $y-z$ ).

Figure 8 provides the details of sign convention for the displacement and rotation components. The 12 parameters $u^{0}, v^{0}, w^{0}, \phi_{x}, \phi_{y}, \phi_{z}, \varepsilon_{y}{ }^{0}, \varepsilon_{z}{ }^{0}, \gamma_{y_{z}}{ }^{0}, \bar{u}, \bar{v}$, and $\bar{w}$ are the functions of $x$. As shown in Figure 8, the displacements $u, v$, and $w$ along the $x$-axis exhibit a linear change.

For the periodic unit with an isosceles trapezoid cross section, the deformed position of any cross section is specified by three displacement components of its four nodes (12 displacement parameters). Considering that the number of free parameters in (1) is 12 , (1) represents the field displacement in the cross-sectional plane for the unit exactly.

According to the displacement components at the origin (located at the center of the unit), the displacement components of node $i$ of the periodic unit can be expanded in a 
Taylor series in the $x$ direction. In any case, the displacement components should not exceed the number of nodal displacements and rotations that characterize the deformation of the periodic unit. For the unit shown in Figure 7, its defor- mation has the characteristics of 24 nodal displacements and rotations. Therefore, the following displacement expansions can be obtained by using only the first two terms of the Taylor series and (1).

$$
\begin{aligned}
u^{i}(x, y, z) & \simeq u^{0}-y^{i} \phi_{z}+z^{i} \phi_{y}+y^{i} z^{i} \bar{u}+x^{i}\left(\partial u^{0}-y^{i} \partial \phi_{z}+z^{i} \partial \phi_{y}+y^{i} z^{i} \partial \bar{u}\right) \\
& \simeq u^{0}-y^{i} \phi_{z}+z^{i} \phi_{y}+y^{i} z^{i} \bar{u}+x^{i}\left(\varepsilon_{x}{ }^{0}-y^{i} \kappa_{y}{ }^{0}+z^{i} \kappa_{z}{ }^{0}+y^{i} z^{i} \partial \bar{u}\right) \\
v^{i}(x, y, z) & \simeq v^{0}+y^{i} \varepsilon_{y}{ }^{0}+z^{i}\left(-\phi_{x}+\frac{1}{2} \gamma_{y z}{ }^{0}\right)+y^{i} z^{i} \bar{v}+x^{i}\left[\partial v^{0}+y^{i} \partial \varepsilon_{y}{ }^{0}+z^{i}\left(-\partial \phi_{x}+\frac{1}{2} \partial \gamma_{y z}{ }^{0}\right)+y^{i} z^{i} \partial \bar{v}\right] \\
& \simeq v^{0}+y^{i} \varepsilon_{y}{ }^{0}+z^{i}\left(-\phi_{x}+\frac{1}{2} \gamma_{y z}{ }^{0}\right)+y^{i} z^{i} \bar{v}+x^{i}\left[\gamma_{x y}{ }^{0}+\phi_{z}+y^{i} \partial \varepsilon_{y}{ }^{0}+z^{i}\left(-\kappa_{x}{ }^{0}+\frac{1}{2} \partial \gamma_{y z}{ }^{0}\right)+y^{i} z^{i} \partial \bar{v}\right] \\
w^{i}(x, y, z) & \simeq w^{0}+z^{i} \varepsilon_{z}{ }^{0}+y^{i}\left(\phi_{x}+\frac{1}{2} \gamma_{y z}{ }^{0}\right)+y^{i} z^{i} \bar{w}+x^{i}\left[\partial w^{0}+z^{i} \partial \varepsilon_{z}{ }^{0}+y^{i}\left(\partial \phi_{x}+\frac{1}{2} \partial \gamma_{y z}{ }^{0}\right)+y^{i} z^{i} \partial \bar{w}\right] \\
& \simeq w^{0}+z^{i} \varepsilon_{z}{ }^{0}+y^{i}\left(\phi_{x}+\frac{1}{2} \gamma_{y z}{ }^{0}\right)+y^{i} z^{i} \bar{w}+x^{i}\left[\gamma_{x z}{ }^{0}-\phi_{y}+z^{i} \partial \varepsilon_{z}{ }^{0}+y^{i}\left(\kappa_{x}{ }^{0}+\frac{1}{2} \partial \gamma_{y z}{ }^{0}\right)+y^{i} z^{i} \partial \bar{w}\right],
\end{aligned}
$$

where $\varepsilon_{x}{ }^{0}=\partial u^{0}, \kappa_{y}{ }^{0}=\partial \phi_{z}, \kappa_{z}{ }^{0}=\partial \phi_{y}, \gamma_{x y}{ }^{0}=\partial v^{0}-\phi_{z}, \gamma_{x z}{ }^{0}=$ $\partial w^{0}+\phi_{y}, \kappa_{x}{ }^{0}=\partial \phi_{x}, \varepsilon_{y}{ }^{0}=\partial v^{0}, \varepsilon_{z}{ }^{0}=\partial w^{0}$, and $\partial \equiv d / d x$.

The classical beam model used in this paper assumes that no warping and distortion of the cross section are observed. Thus, $\bar{u}, \bar{v}$, and $\bar{w}$ do not exist in the beam model. The parameters in (2) related to $\bar{u}, \bar{v}$, and $\bar{w}$ are set equal to zero to make the equivalence of the unit and the beam model, that is,

$$
\bar{u}=\bar{v}=\bar{w}=\partial \bar{u}=\partial \bar{v}=\partial \bar{w}=0 .
$$

The compatibility among the units of the beam model used in this paper requires that strains $\varepsilon_{y}{ }^{0}, \varepsilon_{z}{ }^{0}$, and $\gamma_{y z}{ }^{0}$ in the cross-sectional plane of two adjacent elements be the same at their interfaces. This condition can be satisfied if the following strain derivatives are set to zero.

$$
\partial \varepsilon_{y}{ }^{0}=\partial \varepsilon_{z}{ }^{0}=\partial \gamma_{y z}{ }^{0}=0
$$

The following formula can be obtained by substituting (3) and (4) into (2).

$$
\begin{aligned}
& u^{i}(x, y, z) \simeq u^{0}-y^{i} \phi_{z}+z^{i} \phi_{y}+x^{i}\left(\varepsilon_{x}{ }^{0}-y^{i} \kappa_{y}{ }^{0}+z^{i} \kappa_{z}{ }^{0}\right) \\
& v^{i}(x, y, z) \simeq v^{0}+y^{i} \varepsilon_{y}{ }^{0}+z^{i}\left(-\phi_{x}+\frac{1}{2} \gamma_{y z}{ }^{0}\right)+x^{i}\left(\varepsilon_{y}{ }^{0}-z^{i} \kappa_{x}{ }^{0}\right) \\
& w^{i}(x, y, z) \simeq w^{0}+z^{i} \varepsilon_{z}{ }^{0}+y^{i}\left(\phi_{x}+\frac{1}{2} \gamma_{y z}{ }^{0}\right)+x^{i}\left(\varepsilon_{z}{ }^{0}+y^{i} \kappa_{x}{ }^{0}\right) .
\end{aligned}
$$

The displacement of all nodes in the unit can be calculated by (5). As shown in Figure 9, 24 nodes are found in one unit: $\mathrm{A}-\mathrm{L}$ and $\mathrm{A}^{\prime}-\mathrm{L}^{\prime}$.

4.2. Strain Energy. In accordance with (1), the strain components can be obtained by the Cauchy equation as follows:

$$
\begin{aligned}
\varepsilon_{x} & =\partial u^{0}-y \partial \phi_{z}+z \partial \phi_{y}+y z \partial \bar{u}=\varepsilon_{x}{ }^{0}-y \kappa_{y}{ }^{0}+z \kappa_{z}{ }^{0}+y z \partial \bar{u} \\
\varepsilon_{y} & =\varepsilon_{y}{ }^{0}+z \bar{v} \\
\varepsilon_{z} & =\varepsilon_{z}{ }^{0}+y \bar{w} \\
\gamma_{x y} & =\left(\partial v^{0}-\phi_{z}\right)+y \partial \varepsilon_{y}{ }^{0}+z\left(-\partial \phi_{x}+\frac{1}{2} \partial \gamma_{y z}{ }^{0}\right)+y z \partial \bar{v} \\
& =\gamma_{x y}{ }^{0}+y \partial \varepsilon_{y}{ }^{0}+z\left(-\kappa_{x}{ }^{0}+\frac{1}{2} \partial{\gamma_{y z}}^{0}\right)+y z \partial \bar{v} \\
\gamma_{x z} & =\left(\partial w^{0}-\phi_{y}\right)+z \partial \varepsilon_{z}{ }^{0}+y\left(\partial \phi_{x}+\frac{1}{2} \partial \gamma_{y z}{ }^{0}\right)+y z \partial \bar{w} \\
& =\gamma_{x z}{ }^{0}+z \partial \varepsilon_{z}{ }^{0}+y\left(\kappa_{x}{ }^{0}+\frac{1}{2} \partial \gamma_{y z}{ }^{0}\right)+y z \partial \bar{w}, \\
\gamma_{y z} & =\gamma_{y z}{ }^{0}+y \bar{v}+z \bar{w},
\end{aligned}
$$

where $\varepsilon_{x}{ }^{0}, \varepsilon_{y}{ }^{0}$, and $\varepsilon_{z}{ }^{0}$ are taken to be the principal strains in the $x, y$, and $z$ directions, respectively; $\gamma_{x y}{ }^{0}, \gamma_{y_{z}}{ }^{0}$, and $\gamma_{x z}{ }^{0}$ refer to the transverse shearing strains in the xoy, yoz, and $x o z$ planes, respectively; $\kappa_{x}{ }^{0}$ is the twist; $\kappa_{y}{ }^{0}$ and $\kappa_{z}{ }^{0}$ are the curvature changes in the $y$ and $z$ directions, respectively; and $\partial \equiv d / d x$.

According to (3), the above equations are simplified and the expressions can be obtained as follows:

$$
\begin{aligned}
\varepsilon_{x} & =\varepsilon_{x}{ }^{0}-y \kappa_{y}{ }^{0}+z \kappa_{z}{ }^{0}, \\
\varepsilon_{y} & =\varepsilon_{y}{ }^{0}, \\
\varepsilon_{z} & =\varepsilon_{z}{ }^{0}, \\
\gamma_{x y} & ={\gamma_{x y}}^{0}+y \partial{\varepsilon_{y}}^{0}+z\left(-\kappa_{x}{ }^{0}+\frac{1}{2} \partial \gamma_{y z}{ }^{0}\right), \\
\gamma_{x z} & =\gamma_{x z}{ }^{0}+z \partial \varepsilon_{z}{ }^{0}+y\left(\kappa_{x}{ }^{0}+\frac{1}{2} \partial \gamma_{y z}{ }^{0}\right), \\
\gamma_{y z} & =\gamma_{y z}{ }^{0} .
\end{aligned}
$$




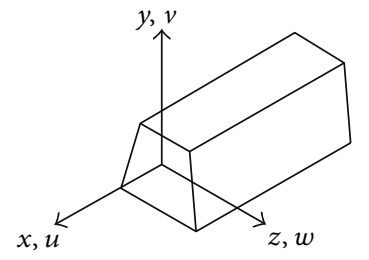

(a) Displacement component

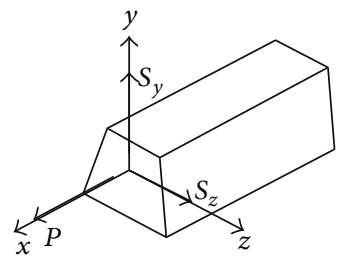

(c) Force component

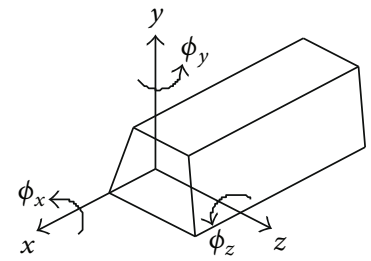

(b) Corner component

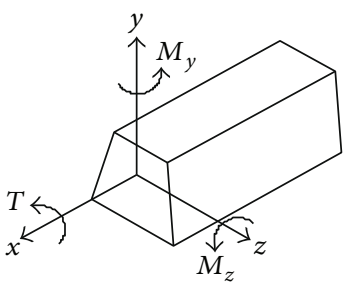

(d) Moment component
Figure 8: Beam element and sign convention.

The axial strain of the rod and cable elements in the unit can be written as follows:

$$
\begin{aligned}
\varepsilon^{(k)}= & \varepsilon_{x}{ }^{(k)} l^{(k) 2}+\varepsilon_{y}{ }^{(k)} m^{(k) 2}+\varepsilon_{z}{ }^{(k)} n^{(k) 2} \\
& +\gamma_{y z}{ }^{(k)} m^{(k)} n^{(k)}+\gamma_{x z}{ }^{(k)} l^{(k)} n^{(k)}+\gamma_{x y}{ }^{(k)} l^{(k)} m^{(k)},
\end{aligned}
$$

where $\varepsilon^{(k)}$ is the axial strain in the $k$ th member; $\varepsilon_{x}{ }^{(k)}, \varepsilon_{y}{ }^{(k)}$, $\varepsilon_{z}{ }^{(k)}, \gamma_{y z}{ }^{(k)}, \gamma_{x z}{ }^{(k)}$, and $\gamma_{x y}{ }^{(k)}$ are the strain components in the coordinate directions evaluated at the member center; $l^{(k)}, m^{(k)}$, and $n^{(k)}$ refer to the direction cosines of the axis of a rod or cable unit in the unit coordinate system of the member $k$.

The strain components of the $k$ th member can be expanded in a Taylor series about the selected origin as follows:

$$
\begin{aligned}
& \varepsilon_{x}{ }^{(k)} \simeq \varepsilon_{x}{ }^{0}-y^{(k)} \kappa_{y}{ }^{0}+z^{(k)} \kappa_{z}{ }^{0}+x^{(k)}\left(\partial \varepsilon_{x}{ }^{0}-y^{(k)} \partial \kappa_{y}{ }^{0}+z^{(k)} \partial \kappa_{z}{ }^{0}\right), \\
& \varepsilon_{y}{ }^{(k)} \simeq \varepsilon_{y}{ }^{0}+x^{(k)} \partial \varepsilon_{y}{ }^{0}+\frac{1}{2}\left(x^{(k)}\right)^{2} \partial^{2} \varepsilon_{y}{ }^{0} \\
& \varepsilon_{z}^{(k)} \simeq \varepsilon_{z}^{0}+x^{(k)} \partial \varepsilon_{z}^{0}+\frac{1}{2}\left(x^{(k)}\right)^{2} \partial^{2} \varepsilon_{z}^{0}, \\
& \gamma_{x y}{ }^{(k)} \simeq \gamma_{x y}{ }^{0}+y^{(k)} \partial \varepsilon_{y}{ }^{0}+z^{(k)}\left(-\kappa_{x}{ }^{0}+\frac{1}{2} \partial \gamma_{y z}{ }^{0}\right) \\
& +x^{(k)}\left[\partial \gamma_{x y}{ }^{0}+y^{(k)} \partial^{2} \varepsilon_{y}{ }^{0}+z^{(k)}\left(-\partial \kappa_{x}{ }^{0}+\frac{1}{2} \partial^{2} \gamma_{y z}{ }^{0}\right)\right], \\
& \gamma_{x z}{ }^{(k)} \simeq \gamma_{x z}{ }^{0}+z^{(k)} \partial \varepsilon_{z}{ }^{0}+y^{(k)}\left(\kappa_{x}^{0}+\frac{1}{2} \partial \gamma_{y z}{ }^{0}\right) \\
& +x^{(k)}\left[\partial \gamma_{x z}{ }^{0}+z^{(k)} \partial^{2} \varepsilon_{z}{ }^{0}+y^{(k)}\left(\partial \kappa_{x}^{0}+\frac{1}{2} \partial^{2} \gamma_{y z}{ }^{0}\right)\right], \\
& \gamma_{y z}{ }^{(k)} \simeq \gamma_{y z}{ }^{0}+x^{(k)} \partial \gamma_{y z}{ }^{0}+\frac{1}{2}\left(x^{(k)}\right)^{2} \partial^{2} \gamma_{y z}{ }^{0},
\end{aligned}
$$

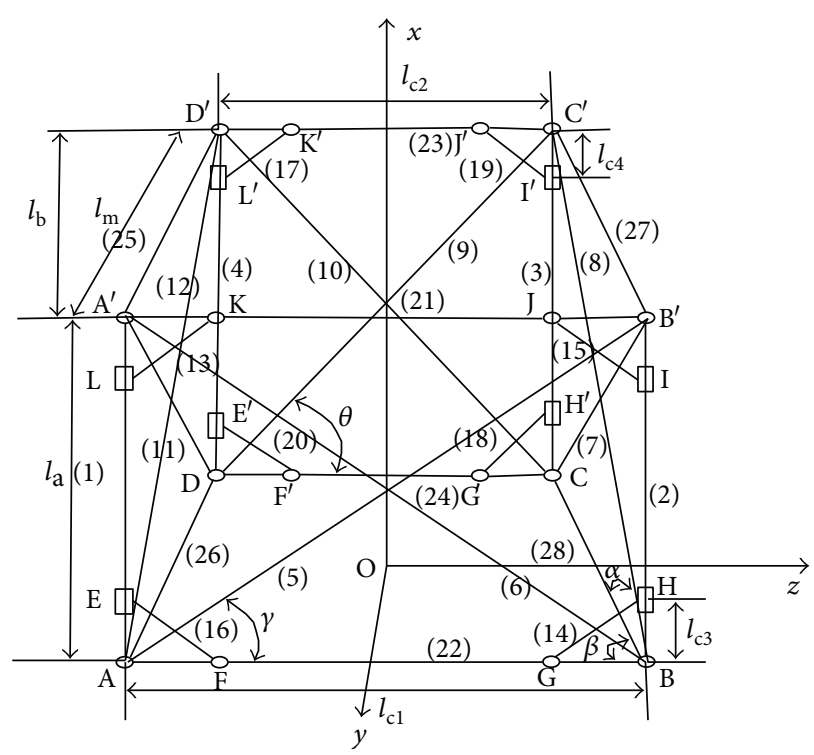

FIgURE 9: Coordinate system of the periodic unit.

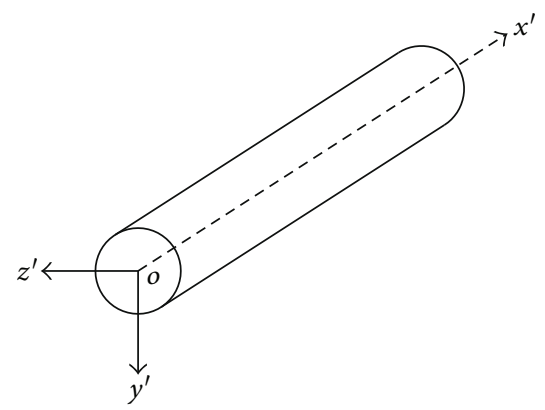

Figure 10: Coordinate system of rod and cable.

where $x^{(k)}, y^{(k)}$, and $z^{(k)}$ are the coordinates of the center of the $k$ th member and $\partial^{2} \equiv d^{2} / d x^{2}$.

Considering that the derivative of the strain is neglected in the displacement expansion of the periodic unit (5), we considered that the strain in the periodic unit is constant. Thus, the derivative of the strain in the upper formula can be deleted. In accordance with (4), the strain components of the $k$ th member can be simplified as follows:

$$
\begin{aligned}
\varepsilon_{x}{ }^{(k)} & \simeq \varepsilon_{x}{ }^{0}-y^{(k)} \kappa_{y}{ }^{0}+z^{(k)} \kappa_{z}{ }^{0}, \\
\varepsilon_{y}{ }^{(k)} & \simeq \varepsilon_{y}{ }^{0}, \\
\varepsilon_{z}{ }^{(k)} & \simeq \varepsilon_{z}{ }^{0}, \\
\gamma_{x y}{ }^{(k)} & \simeq \gamma_{x y}{ }^{0}+y^{(k)} \partial \varepsilon_{y}{ }^{0}+z^{(k)}\left(-\kappa_{x}{ }^{0}+\frac{1}{2} \partial \gamma_{y z}{ }^{0}\right), \\
\gamma_{x z}{ }^{(k)} & \simeq \gamma_{x z}{ }^{0}+z^{(k)} \partial \varepsilon_{z}{ }^{0}+y^{(k)}\left(\kappa_{x}{ }^{0}+\frac{1}{2} \partial \gamma_{y z}{ }^{0}\right), \\
\gamma_{y z}{ }^{(k)} & \simeq \gamma_{y z}{ }^{0},
\end{aligned}
$$

The coordinate system of the rods and the cables is shown in Figure 10. The coordinate system of the unit is presented in Figure 9, where $\gamma$ is the angle between the outer 
cable and the outer rail, $\theta$ is the angle between the inner cable and the inner rail, $\alpha$ is the angle between the central connection side cable and the central connecting $\operatorname{rod}$, and $\beta$ is the angle between the central connecting rod and rail. The crank connecting rod is arranged at a $45^{\circ}$ angle.

In accordance with (8), the axial strain of each component can be obtained as follows:

$$
\begin{aligned}
& \varepsilon^{(1)}=\varepsilon_{x}{ }^{(1)}, \\
& \varepsilon^{(2)}=\varepsilon_{x}{ }^{(2)}, \\
& \mathcal{E}^{(3)}=\varepsilon_{x}{ }^{(3)}, \\
& \cdots, \\
& \varepsilon^{(28)}=\varepsilon_{y}{ }^{(28)}(-\sin \beta)^{2}+\varepsilon_{z}{ }^{(28)} \cos ^{2} \beta+\gamma_{y z}{ }^{(28)} \sin \beta \cos \beta .
\end{aligned}
$$

Each point of the rods and the cables possesses the same strain. Therefore, their strain can be expressed by the strain of the midpoint. $l_{b}$ is the length of the central connecting rod in the $y$ direction; $l_{m}$ is defined as the length of the central rod; $l_{c 1}$ and $l_{c 2}$ are given by the length of the outer and inner rails. $l_{m}{ }^{2}=\left(l_{c 1}-l_{c 2} / 2\right)^{2}+l_{b}{ }^{2}, l_{d}=(1 / 2)\left(l_{c 1}+l_{c 2}\right), l_{e}=(1 / 2)$ $\left(l_{c 1}-l_{c 3}\right)$, and $l_{f}=(1 / 2)\left(l_{c 2}-l_{c 4}\right)$, where $l_{c 3}$ and $l_{c 4}$ are the distances between the slider and the node of the unit.

By taking the coordinate values of each middle point in the yoz plane into (10), we can obtain the axial strain expressions of vertical bars (1-4), cables (5-12), cranks (13-20), rails (21-24), and central connecting rods (25-28) as follows:

$$
\begin{aligned}
\varepsilon_{x}{ }^{(1)} & =\varepsilon_{x}{ }^{0}-\frac{l_{b}}{2} \kappa_{z}{ }^{0}-\frac{l_{c 1}}{2} \kappa_{y}{ }^{0}, \\
\varepsilon_{x}{ }^{(2)} & =\varepsilon_{x}{ }^{0}-\frac{l_{b}}{2} \kappa_{z}^{0}+\frac{l_{c 1}}{2} \kappa_{y}^{0}, \\
\cdots, & \\
\varepsilon_{x}{ }^{(18)} & =\varepsilon_{x}{ }^{(19)}=\varepsilon_{x}{ }^{0}+\frac{l_{b}}{2} \kappa_{y}{ }^{0}+\frac{l_{f}}{2} \kappa_{z}^{0}, \\
\varepsilon_{z}{ }^{(18)} & =\varepsilon_{z}{ }^{(19)}=\varepsilon_{z}{ }^{0}, \\
\gamma_{x z}{ }^{(18)} & =\gamma_{x z}{ }^{(19)}=\gamma_{x z}{ }^{0}-\frac{l_{b}}{2}\left(\kappa_{x}{ }^{0}+\frac{1}{2} \partial \gamma_{y z}{ }^{0}\right)+\frac{l_{f}}{2} \partial \varepsilon_{z}{ }^{0} .
\end{aligned}
$$

In accordance with (11) and (12), the axial strain of each component can be written as follows:

$$
\begin{aligned}
& \varepsilon^{(1)}=\varepsilon_{x}{ }^{0}-\frac{l_{b}}{2} \kappa_{z}{ }^{0}-\frac{l_{c 1}}{2} \kappa_{y}{ }^{0}, \\
& \varepsilon^{(2)}=\varepsilon_{x}{ }^{0}-\frac{l_{b}}{2} \kappa_{z}{ }^{0}+\frac{l_{c 1}}{2} \kappa_{y}{ }^{0}, \\
& \varepsilon^{(3)}=\varepsilon_{x}{ }^{0}+\frac{l_{b}}{2} \kappa_{z}{ }^{0}+\frac{l_{c 2}}{2} \kappa_{y}{ }^{0}, \\
& \cdots, \\
& \varepsilon^{(28)}=\varepsilon_{y}{ }^{0} \sin ^{2} \beta+\varepsilon_{z}{ }^{0} \cos ^{2} \beta+\gamma_{y z}{ }^{0} \sin \beta \cos \beta,
\end{aligned}
$$

The strain energy of each component is as follows:

$$
U_{\varepsilon}{ }^{(k)}=\frac{1}{2} E^{(k)} A^{(k)} l^{(k)}\left(\varepsilon^{(k)}\right)^{2}
$$

where $E^{(k)}$ signifies the elastic modulus of the $k$ th member, $A^{(k)}$ means the cross-sectional area of the $k$ th member, $l^{(k)}$ is the length of the $k$ th member, and $\varepsilon^{(k)}$ is the principal strain of the $k$ th member.

Therefore, the total strain energy of the unit can be expressed as

$$
\begin{aligned}
U_{\varepsilon}= & \sum_{\text {members }} U_{\varepsilon}{ }^{(k)}=\frac{1}{2} \sum_{\text {members }} E^{(k)} A^{(k)} l^{(k)}\left(\varepsilon^{(k)}\right)^{2} \\
= & \frac{1}{2} \times \frac{1}{2} E_{l} A_{l} l_{l} \sum_{k=1}^{4}\left(\varepsilon^{(k)}\right)^{2}+\frac{1}{2} E_{d^{\prime}} A_{d^{\prime}} l_{d 1^{\prime}} \sum_{k=5}^{6}\left(\varepsilon^{(k)}\right)^{2} \\
& +\frac{1}{2} E_{d^{\prime}} A_{d^{\prime}} l_{d 2^{\prime}} \sum_{k=9}^{10}\left(\varepsilon^{(k)}\right)^{2}+\frac{1}{2} \\
& \times \frac{1}{2} E_{d^{\prime}} A_{d^{\prime}} l_{d 3^{\prime}} \sum_{k=7,8,11,12}\left(\varepsilon^{(k)}\right)^{2} \\
& +\frac{1}{2} E_{\mathrm{m}^{\prime}} A_{m^{\prime}} l_{m 1^{\prime}} \sum_{k=13}^{16}\left(\varepsilon^{(k)}\right)^{2}+\frac{1}{2} E_{\mathrm{m}^{\prime}} A_{m^{\prime}} l_{m 2^{\prime}} \sum_{k=17}^{20}\left(\varepsilon^{(k)}\right)^{2} \\
& +\frac{1}{2} E_{\mathrm{n}^{\prime}} A_{n^{\prime}} l_{n 1^{\prime}} \sum_{k=21}^{22}\left(\varepsilon^{(k)}\right)^{2}+\frac{1}{2} E_{\mathrm{n}^{\prime}} A_{n^{\prime}} l_{n 2^{\prime}} \sum_{k=23}^{24}\left(\varepsilon^{(k)}\right)^{2} \\
& +\frac{1}{2} \times \frac{1}{2} E_{f^{\prime}} A_{f^{\prime}} l_{f^{\prime}} \sum_{25}^{28}\left(\varepsilon^{(k)}\right)^{2},
\end{aligned}
$$

where the subscripts $l, d^{\prime}, m^{\prime}, n^{\prime}$, and $f^{\prime}$ stand for the vertical bar, cable, crank, rail, and central connecting rod, respectively; $d 1^{\prime}, d 2^{\prime}$, and $d 3^{\prime}$ refer to the outer cable, the inner cable, and the cable in the plane of the central connection unit, respectively; $m 1^{\prime}$ and $m 2^{\prime}$ stand for the outer and inner crank connecting rods, respectively; and $n 1^{\prime}$ and $n 2^{\prime}$ are the outer and inner bars, respectively.

As a result of the vertical pole, the stay cable and the central connecting rod are shared by two adjacent units and their strain energy is taken as half of the original values.

The classical beam theory assumes that the fibers in the cross section do not interact. Thus, no $\varepsilon_{y}{ }^{0}, \varepsilon_{z}{ }^{0}$, and $\gamma_{y z}{ }^{0}$ exist in the beam model. The stress related to the strain in the cross section is set equal to zero to make the equivalent of the unit and the beam model, that is,

$$
\frac{\partial U_{\varepsilon}}{\partial \varepsilon_{y}{ }^{0}}=\frac{\partial U_{\varepsilon}}{\partial \varepsilon_{z}{ }^{0}}=\frac{\partial U_{\varepsilon}}{\partial \gamma_{y z}{ }^{0}}=0
$$

In accordance with (14) and (15), the strain energy of the unit can be expressed as follows: 


$$
\begin{aligned}
U_{\varepsilon}= & \sum_{\text {members }} U_{\varepsilon}{ }^{(k)}=\frac{1}{2} \sum_{\text {members }} E^{(k)} A^{(k)} l^{(k)}\left(\varepsilon^{(k)}\right)^{2} \\
= & \frac{1}{2} C_{11}\left(\varepsilon_{x}{ }^{0}\right)^{2}+\frac{1}{2} C_{22}\left(\gamma_{x z}{ }^{0}\right)^{2}+\frac{1}{2} C_{33}\left(\gamma_{x y}{ }^{0}\right)^{2} \\
& +\frac{1}{2} C_{44}\left(\kappa_{x}{ }^{0}\right)^{2}+\frac{1}{2} C_{55}\left(\kappa_{y}{ }^{0}\right)^{2}+\frac{1}{2} C_{66}\left(\kappa_{z}{ }^{0}\right)^{2} \\
& +\frac{1}{2} C_{15} \varepsilon_{x}{ }^{0} \kappa_{y}{ }^{0}+\frac{1}{2} C_{24} \gamma_{x z}{ }^{0} \kappa_{x}{ }^{0},
\end{aligned}
$$

where

$$
\begin{aligned}
& C_{11}=2\left(E_{l} A_{l} l_{l}+E_{d^{\prime}} A_{d^{\prime}} l_{d 1^{\prime}} \sin ^{4} \gamma+E_{d^{\prime}} A_{d^{\prime}} l_{d 2^{\prime}} \sin ^{4} \theta\right. \\
& \left.+E_{d^{\prime}} A_{d^{\prime}} l_{d 3^{\prime}} \sin ^{4} \alpha+\frac{1}{4} E_{m^{\prime}} A_{m^{\prime}} l_{m 1^{\prime}}+\frac{1}{4} E_{m^{\prime}} A_{m^{\prime}} l_{m 2^{\prime}}\right), \\
& C_{22}=2\left(E_{d^{\prime}} A_{d^{\prime}} l_{d 1^{\prime}} \sin ^{2} \gamma \cos ^{2} \gamma+E_{d^{\prime}} A_{d^{\prime}} l_{d 2^{\prime}} \sin ^{2} \theta \cos ^{2} \theta\right. \\
& +\frac{1}{4} E_{m^{\prime}} A_{m^{\prime}} l_{m 1^{\prime}}+\frac{1}{4} E_{m^{\prime}} A_{m^{\prime}} l_{m 2^{\prime}} \\
& \left.+E_{d^{\prime}} A_{d^{\prime}} l_{d 3^{\prime}} \sin ^{2} \alpha \cos ^{2} \beta\right) \text {, } \\
& C_{33}=2\left(E_{d^{\prime}} A_{d^{\prime}} l_{d 3^{\prime}} \sin ^{2} \alpha \cos ^{2} \alpha \sin ^{2} \beta\right), \\
& C_{44}=2\left(\frac{1}{4} E_{d^{\prime}} A_{d^{\prime}} l_{d 1^{\prime}} \sin ^{2} \gamma \cos ^{2} \gamma l_{b}^{2}\right. \\
& +\frac{1}{4} E_{d^{\prime}} A_{d^{\prime}} l_{d 2^{\prime}} \sin ^{2} \theta \cos ^{2} \theta l_{b}^{2} \\
& +\frac{1}{4} E_{d^{\prime}} A_{d^{\prime}} l_{d 3^{\prime}} \sin ^{2} \alpha \cos ^{2} \alpha \sin ^{2} \beta l_{d}^{2} \\
& \left.+\frac{1}{16} E_{m^{\prime}} A_{m^{\prime}} l_{m 1} l_{b}^{2}+\frac{1}{16} E_{m} A_{m^{\prime}} l_{m 2^{\prime}} l_{b}^{2}\right), \\
& C_{55}=2\left(\frac{1}{8} E_{l} A_{l} l_{l}\left(l_{c 1}^{2}+l_{c 2}^{2}\right)+\frac{1}{4} E_{d^{\prime}} A_{d^{\prime}} l_{d 1^{\prime}} \sin ^{4} \gamma l_{b}^{2}\right. \\
& +\frac{1}{4} E_{d^{\prime}} A_{d^{\prime}} l_{d 2^{\prime}} \sin ^{4} \theta l_{b}^{2}+\frac{1}{16} E_{m^{\prime}} A_{m^{\prime}} l_{m 1^{\prime}} l_{b}^{2} \\
& \left.+\frac{1}{16} E_{m^{\prime}} A_{m^{\prime}} l_{m 2^{\prime}} l_{b}^{2}\right) \\
& C_{66}=2\left(\frac{1}{4} E_{l} A_{l} l_{l} l_{b}^{2}+\frac{1}{4} E_{d^{\prime}} A_{d^{\prime}} l_{d 3^{\prime}} \sin ^{4} \alpha l_{b}^{2}+\frac{1}{16} E_{m^{\prime}} A_{m^{\prime}} l_{m 1^{\prime}} l_{e}^{2}\right. \\
& \left.+\frac{1}{16} E_{m^{\prime}} A_{m^{\prime}} l_{m 2^{\prime}} l_{f}^{2}\right) \\
& C_{15}=2\left(-E_{d^{\prime}} A_{d^{\prime}} l_{d 1^{\prime}} \sin ^{4} \gamma l_{b}-E_{d^{\prime}} A_{d^{\prime}} l_{d 2^{\prime}} \sin ^{4} \theta l_{b}\right. \\
& \left.-\frac{1}{4} E_{m^{\prime}} A_{m^{\prime}} l_{m 1^{\prime}} l_{b}+\frac{1}{4} E_{m^{\prime}} A_{m^{\prime}} l_{m 2^{\prime}} l_{b}\right), \\
& C_{24}=2\left(E_{d^{\prime}} A_{d^{\prime}} l_{d 1^{\prime}} \sin ^{2} \gamma \cos ^{2} \gamma+E_{d^{\prime}} A_{d^{\prime}} l_{d 2^{\prime}} \sin ^{2} \theta \cos ^{2} \theta\right. \\
& +\frac{1}{4} E_{m} A_{m^{\prime}} l_{m 1^{\prime}} l_{b}-\frac{1}{4} E_{m^{\prime}} A_{m^{\prime}} l_{m 2^{\prime}} l_{b} \\
& \text { - } E_{d^{\prime}} A_{d^{\prime}} l_{d 3^{\prime}} \sin \alpha \cos \beta l_{d} \text { ). }
\end{aligned}
$$

4.3. Kinetic Energy. The kinetic energy is calculated by considering the motion of the rigid body only. The kinetic energy of the rods and cables is as follows:

$$
\begin{aligned}
K^{(k)}= & \frac{1}{6} \omega^{2} \rho^{(k)} A^{(k)} l^{(k)} \\
& \cdot\left[u^{i} u^{i}+u^{i} u^{j}+u^{j} u^{j}+v^{i} v^{i}+v^{i} v^{j}\right. \\
& \left.\quad+v^{j} v^{j}+w^{i} w^{i}+w^{i} w^{j}+w^{j} w^{j}\right],
\end{aligned}
$$

where $u^{i}, v^{i}, w^{i}, u^{j}, v^{j}$, and $w^{j}$ are the nodal displacements of the $k$ th member; $\omega$ is the circular frequency of vibration of the unit; and $\rho^{(k)}$ is the density of the $k$ th member.

The kinetic energy of hinges and sliders can be expressed as follows:

$$
K^{(m)}=\frac{1}{2} \omega^{2} m^{(m)}\left[\boldsymbol{u}^{(m)} \boldsymbol{u}^{(m)}+\boldsymbol{v}^{(m)} \boldsymbol{v}^{(m)}+\boldsymbol{w}^{(m)} \boldsymbol{w}^{(m)}\right],
$$

where $u^{(m)}, v^{(m)}$, and $w^{(m)}$ are the nodal displacements of the hinges and sliders and $m^{(m)}$ is their mass.

The total kinetic energy of the unit is given by

$$
K=\sum_{\text {members }}\left(K^{(k)}+K^{(m)}\right)
$$

Considering that the rigid body motion is the main part of kinetic energy, the strain term in (5) is neglected when calculating the kinetic energy of the periodic unit. Thus, the formula for the nodal displacement used to solve kinetic energy can be obtained as follows:

$$
\begin{aligned}
u^{i}(x, y, z) & \simeq u^{0}-y^{i} \phi_{z}+z^{i} \phi_{y}, \\
v^{i}(x, y, z) & \simeq v^{0}-z^{i} \phi_{x}, \\
w^{i}(x, y, z) & \simeq w^{0}+y^{i} \phi_{x} .
\end{aligned}
$$

The kinetic energy of cross bars, vertical rods, cables, hinges, sliding blocks, and crank connecting rods $\sum K_{b}$, $\sum K_{l}, \sum K_{d}, \sum K_{m 1}, \sum K_{m 2}$, and $\sum K_{m}$ can be obtained by using (20), (21), and (22).

The longitudinal rods, central connecting rods, central link unit cables, hinges, and sliders are shared by two adjacent units, and their kinetic energy is taken as half of the original values.

In accordance with (21), the total kinetic energy of the unit is obtained as follows:

$$
K=\sum K_{b}+\sum K_{l}+\sum K_{d}+\sum K_{m}+\sum K_{m 1}+\sum K_{m 2} .
$$

Equation (24) is the specific expression of the total kinetic energy of the periodic unit, as shown below.

$$
\begin{aligned}
K= & \frac{1}{2} B_{1} \omega^{2}\left(u^{0} u^{0}+v^{0} v^{0}+w^{0} w^{0}\right)+\frac{1}{2} B_{2} \omega^{2}\left(\phi_{x} \phi_{x}+\phi_{y} \phi_{y}\right) \\
& +\frac{1}{2} B_{3} \omega^{2}\left(\phi_{x} \phi_{x}+\phi_{z} \phi_{z}\right)+\frac{1}{2} B_{4} \omega^{2}\left(w^{0} \phi_{x}-u^{0} \phi_{z}\right) .
\end{aligned}
$$

where 


$$
\begin{aligned}
B_{1}= & 2\left(\rho_{l} A_{l} l_{l}+\rho_{b 1} A_{b 1} l_{b 1}+\rho_{b 2} A_{b 2} l_{b 2}+\rho_{b 3} A_{b 3} l_{b 3}+\rho_{d 3} A_{d 3} l_{d 3}+\rho_{d 1} A_{d 1} l_{d 1}+\rho_{d 2} A_{d 2} l_{d 2}+2 \rho_{m 1} A_{m 1} l_{m 1}+2 \rho_{m 2} A_{m 2} l_{m 2}+2 m_{1}+2 m_{2}\right) \\
B_{2}= & 2\left(\frac{l_{c 1}}{2}\right)^{2}\left(\frac{1}{3} \rho_{b 1} A_{b 1} l_{b 1}+\frac{1}{3} \rho_{b 2} A_{b 2} l_{b 2}+\frac{1}{2} \rho_{l} A_{l} l_{l}+\frac{1}{3} \rho_{d 3} A_{d 3} l_{d 3}+\frac{1}{3} \rho_{d 1} A_{d 1} l_{d 1}+\frac{2}{3} \rho_{m 1} A_{m 1} l_{m 1}+m_{1}+m_{2}\right) \\
& +2\left(\frac{l_{c 2}}{2}\right)^{2}\left(\frac{1}{3} \rho_{b 1} A_{b 1} l_{b 1}+\frac{1}{3} \rho_{b 2} A_{b 2} l_{b 2}+\frac{1}{2} \rho_{l} A_{l} l_{l}+\frac{1}{3} \rho_{d 3} A_{d 3} l_{d 3}+\frac{1}{3} \rho_{d 2} A_{d 2} l_{d 2}+\frac{2}{3} \rho_{m 2} A_{m 2} l_{m 2}+m_{1}+m_{2}\right) \\
& +2\left(\frac{l_{c 1}}{2} \cdot \frac{l_{c 2}}{2}\right)\left(\frac{1}{3} \rho_{b 1} A_{b 1} l_{b 1}+\frac{1}{3} \rho_{d 3} A_{d 3} l_{d 3}\right) \\
B_{3}= & 2\left(\frac{l_{b}}{2}\right)^{2}\left(\frac{1}{3} \rho_{b 1} A_{b 1} l_{b 1}+\rho_{b 2} A_{b 2} l_{b 2}+\rho_{b 3} A_{b 3} l_{b 3}+\rho_{l} A_{l} l_{l}+\frac{1}{3} \rho_{d 3} A_{d 3} l_{d 3}+\rho_{d 1} A_{d 1} l_{d 1}+\rho_{d 2} A_{d 2} l_{d 2}\right. \\
& \left.+2 \rho_{m 1} A_{m 1} l_{m 1}+2 \rho_{m 2} A_{m 2} l_{m 2}+2 m_{1}+2 m_{2}\right) \\
B_{4}= & 2 \frac{l_{b}}{2}\left(2 \rho_{b 2} A_{b 2} l_{b 2}-2 \rho_{b 3} A_{b 3} l_{b 3}+2 \rho_{d 1} A_{d 1} l_{d 1}-2 \rho_{d 2} A_{d 2} l_{d 2}\right)
\end{aligned}
$$

The subscripts b1, b2, and b3 stand for the central connecting rod, outer rail, and inner rail, respectively; $l$ stands for the vertical bar; $\mathrm{d} 1, \mathrm{~d} 2$, and $\mathrm{d} 3$ stand for the outer cable, the inner cable, and the cable in the plane of the central connection unit, respectively; $m_{1}$ and $m_{2}$ stand for the hinge and the slider, respectively; and $\mathrm{m} 1$ and $\mathrm{m} 2$ stand for the outer and inner crank connecting rods, respectively.

\section{Establishment of the Equivalent Model Based on the Continuous Beam Theory}

5.1. Beam Strain Energy. The strain energy of the periodic unit includes the coupling terms between the stretching and lateral bending as well as the coupling terms between torsion and shearing in Section 4.1. Therefore, the unit needs to be equivalent to the anisotropic beam model.

The strain energy of an anisotropic beam can be expressed as

$$
U_{c}=\frac{1}{2} \int_{l} \Gamma^{T} D \Gamma d x,
$$

where $\Gamma$ is the strain of the neutral axis of the beam, which can be written as

$$
\Gamma=\left\{\varepsilon_{x 0}, \gamma_{x z 0}, \gamma_{x y 0}, \kappa_{x 0}, \kappa_{y 0}, \kappa_{z 0}\right\}^{T},
$$

where $\kappa_{x 0}$ refers to the twist; $\kappa_{y 0}$ and $\kappa_{z 0}$ are the curvature changes in the $y$ and $z$ directions, respectively; $\gamma_{x y 0}$ and $\gamma_{x z 0}$ signify the transverse shearing strain in the xoy and $x o z$ planes, respectively; and $\varepsilon_{x 0}$ means the principal strain in the $x$ direction.

The strains of the equivalent beam model $\varepsilon_{\mathrm{x}}^{0}, \gamma_{x z}^{0}, \gamma_{x y}^{0}$, $\kappa_{x}^{0}, \kappa_{y}^{0}$, and $\kappa_{z}^{0}$ are equal to the strains at the center of the periodic unit.

The matrix $\mathbf{D}$ is taken to be the stiffness matrix of the continuous beam, which can be defined as follows:

$$
\mathbf{D}=\left[\begin{array}{cccccc}
E A^{\prime} & \eta_{12} & \eta_{13} & \eta_{14} & \eta_{15} & \eta_{16} \\
& G A_{z}^{\prime} & \eta_{23} & \eta_{24} & \eta_{25} & \eta_{26} \\
& & G A_{y}^{\prime} & \eta_{34} & \eta_{35} & \eta_{36} \\
& & & G J^{\prime} & \eta_{45} & \eta_{46} \\
& & & & E I_{y}^{\prime} & \eta_{56} \\
& & & & & E I_{z}^{\prime}
\end{array}\right]
$$

where $E A^{\prime}, G A_{x}^{\prime}, G A_{y}^{\prime}, G J^{\prime}, E I_{x}^{\prime}$, and $E I_{y}^{\prime}$ stand for the stiffness of the stretching, shearing, twisting, and bending of the equivalent beam model and $\eta_{i j}(i, j=1, \ldots, 5, i \neq j)$ is the coupling coefficient of each stiffness.

5.2. Beam Kinetic Energy. The displacement strains related to $\varepsilon_{y}{ }^{0}, \varepsilon_{z}{ }^{0}$, and $\gamma_{y_{z}}{ }^{0}$ are disregarded due to the linear relationship of displacement. The kinetic energy of the anisotropic continuous beam model can be expressed as follows [40]:

$$
\begin{aligned}
K_{c}=\frac{1}{2} l_{l} \omega^{2} & {\left[m_{11}\left(u^{0} u^{0}+v^{0} v^{0}+w^{0} w^{0}\right)\right.} \\
& +2 m_{12}\left(-u^{0} \phi_{z}+w^{0} \phi_{x}\right)+2 m_{13}\left(u^{0} \phi_{y}-v^{0} \phi_{x}\right) \\
& -2 m_{23} \phi_{y} \phi_{z}+m_{22}\left(\phi_{x} \phi_{x}+\phi_{y} \phi_{y}\right) \\
& \left.+m_{33}\left(\phi_{x} \phi_{x}+\phi_{z} \phi_{z}\right)\right]
\end{aligned}
$$

where $m_{11}, m_{12}, m_{13}, m_{22}, m_{23}$, and $m_{33}$ are the equivalent mass parameters of the beam model and $\omega$ means the vibration angular frequency of the beam model.

5.3. Establishment of the Continuous Beam Equivalent Model. The length of the equivalent beam model is set equal to the length of the periodic unit $\left(l_{l}\right)$. The principle of equal strain energy and (17), (26), (27), and (28) indicate that the stiffness matrix of the equivalent beam model can be expressed as 
TABLE 1: Material of the unit.

\begin{tabular}{llllcc}
\hline Structure & Cross bar & Longitudinal rod & Hornblock & Slider & Stay cables \\
\hline Material & Aluminum alloy & Aluminum alloy & Aluminum alloy & Aluminum alloy & Kevlar \\
\hline
\end{tabular}

TABLE 2: Structural parameters of the unit.

\begin{tabular}{|c|c|c|c|}
\hline Parameter name & Value & Parameter name & Value \\
\hline Diameter of rod (mm) & $40 / 38$ & Diameter of cable (mm) & 2 \\
\hline Length of central connecting rod (mm) & 1295.4 & Angle $\gamma\left({ }^{\circ}\right)$ & 45.75 \\
\hline Length of outer rail (mm) & 2704.1 & Angle $\theta\left(^{\circ}\right)$ & 49.55 \\
\hline \multirow{2}{*}{ Length of inner rail (mm) } & \multirow{2}{*}{2366.4} & Angle $\alpha\left(^{\circ}\right)$ & 64.98 \\
\hline & & Angle $\beta\left(^{\circ}\right)$ & 82.51 \\
\hline$l_{c 3}(\mathrm{~mm})$ & 476.5 & Modulus of elasticity of bar $E_{l}\left(E_{m}\right)(\mathrm{GPa})$ & 70 \\
\hline$l_{c 4}(\mathrm{~mm})$ & 476.5 & Modulus of elasticity of cable $E_{d}(\mathrm{GPa})$ & 500 \\
\hline Length of vertical bar (mm) & 2776 & Density of bar $\rho_{l}\left(\rho_{b 1}, \rho_{b 2}, \rho_{b 3}\right)\left(\mathrm{kg} / \mathrm{m}^{3}\right)$ & 2700 \\
\hline Length of crank connecting link (mm) & 673.8 & Density of cable $\rho_{d 1}\left(\rho_{d 2}, \rho_{d 3}\right)\left(\mathrm{kg} / \mathrm{m}^{3}\right)$ & 1570 \\
\hline
\end{tabular}

TABLE 3: Stiffness parameters of the beam model.

\begin{tabular}{|c|c|c|c|c|c|c|c|}
\hline $\begin{array}{l}\text { Bending rigidity } \\
E I_{z}^{\prime}\left(N \cdot m^{2}\right)\end{array}$ & $\begin{array}{l}\text { Bending rigidity } \\
\qquad E_{y}^{\prime}\left(N \cdot m^{2}\right)\end{array}$ & $\begin{array}{l}\text { Torsional rigidity } \\
\qquad G J^{\prime}(N \cdot m)\end{array}$ & $\begin{array}{l}\text { Shearing rigidity } \\
\qquad G A_{z}^{\prime}(N)\end{array}$ & $\begin{array}{l}\text { Shearing rigidity } \\
\qquad G A_{y}^{\prime}(N)\end{array}$ & $\begin{array}{l}\text { Axial rigidity } \\
\qquad E A^{\prime}(N)\end{array}$ & $\begin{array}{c}\text { Stiffness } \\
\text { coupling } \\
\text { coefficient } \\
\eta_{15}\end{array}$ & $\begin{array}{c}\text { Stiffness } \\
\text { coupling } \\
\text { coefficient } \\
\eta_{15}\end{array}$ \\
\hline $8.0 \times 10^{6}$ & $2.9 \times 10^{7}$ & $1.5 \times 10^{6}$ & $2.9 \times 10^{6}$ & $0.2 \times 10^{6}$ & $2.1 \times 10^{7}$ & $-0.7 \times 10^{6}$ & $0.2 \times 10^{6}$ \\
\hline
\end{tabular}

follows: $E A^{\prime}=C_{11} / l_{l}, G A_{z}^{\prime}=C_{22} / l_{l}, G A_{y}^{\prime}=C_{33} / l_{l}, G J^{\prime}=C_{44} / l_{l}$, $E I_{y}^{\prime}=C_{55} / l_{l}, E I_{z}^{\prime}=C_{66} / l_{l}, \eta_{15}=C_{15} / 2 l_{l}$, and $\eta_{24}=C_{24} / 2 l_{l}$; the other items of $\eta_{i j}(i, j=1, \ldots, 5, i \neq j)$ are set equal to zero.

The principle of equal kinetic energy and (24) and (29) present that the mass parameters of the equivalent beam model can be written as follows: $m_{11}=B_{1} / l_{l}, m_{22}=B_{2} / l_{l}$, $m_{33}=B_{3} / l_{l}, m_{12}=B_{4} / 2 l_{l}$, and $m_{13}=m_{23}=0$.

The equivalent beam model of the periodic unit is established through the preceding analysis. The equivalent continuum model of the double-layer hoop deployable antenna can be obtained by assembling several equivalent beam models in the circumferential direction in accordance with the geometric topology of the original structure.

\section{Equivalent Dynamic Model Validation and Application}

6.1. Validation of the Equivalent Beam Model. The geometry, physics, and material parameters of the anisotropic beam elements, which are needed to be input in the finite element software to establish the anisotropic beam element in the finite element software, are derived on the basis of the parameters of the stiffness matrix and the inertia matrix solved using the equivalent method obtained above. In this way, we can establish the equivalent beam model obtained above in the finite element software. The dynamic characteristics of the unit are analyzed using the equivalent beam model, finite element model, and modal test. The finite element software ABAQUS was used in this paper. First, the equivalent beam models of the rods of the unit that contains elastic hinges were established in Section 3. The other bars in the unit were also simulated by the beam model. The B31 element was used in the software to simulate the beam model. The cables were simulated with the T3D2 element, which can only withstand tension in the software. The corner points and sliders were modeled with the mass element in the software. The total degree of freedom per node is six. The first two natural frequencies of the unit are obtained through theoretical calculation, simulation, and experiment. The correctness of the equivalent continuum beam model of the unit is verified through the comparison among the simulation, theoretical calculation, and test results.

6.1.1. Theoretical Equivalent Calculation. The material selection and the geometric parameters of the unit are shown in Tables 1 and 2, respectively.

The mass of the corner blocks and the sliders can be expressed as follows: $m_{1}=0.1 \mathrm{Kg}$ and $m_{2}=0.1 \mathrm{Kg}$. By substituting the parameters given above into the expressions of the equivalent stiffness and the equivalent mass, we can acquire the equivalent parameters shown in Tables 3 and 4.

6.1.2. Test Verification. A double-layer deployable antenna unit mechanism is developed to verify the rationality of the design of the double-layer antenna. The folded state and the fully expanded state of the unit are shown in Figure 11. 
TABLE 4: Mass parameters of the beam model.

\begin{tabular}{lccc}
\hline $\begin{array}{l}\text { Unit linear } \\
\text { density } m_{11} \\
(\mathrm{~kg} / \mathrm{m})\end{array}$ & $\begin{array}{c}\text { Rotational } \\
\text { inertia coefficient } \\
m_{22}(\mathrm{~kg} / \mathrm{m})\end{array}$ & $\begin{array}{c}\text { Rotational } \\
\text { inertia coefficient } \\
m_{33}(\mathrm{~kg} / \mathrm{m})\end{array}$ & $\begin{array}{c}\text { Inertia } \\
\text { coupling } \\
\text { coefficient } \\
m_{12}\end{array}$ \\
\hline 3.30 & 3.24 & 1.29 & 0.05 \\
\hline
\end{tabular}

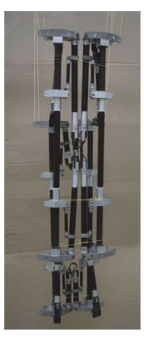

(a) Folded state

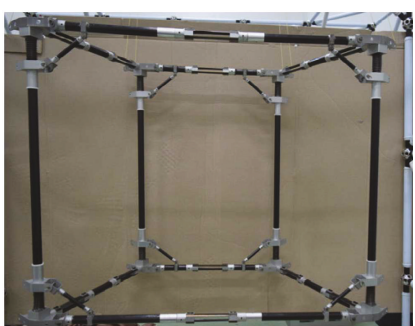

(b) Expanded state
FIGURE 11: Double-layer deployable antenna unit mechanism.
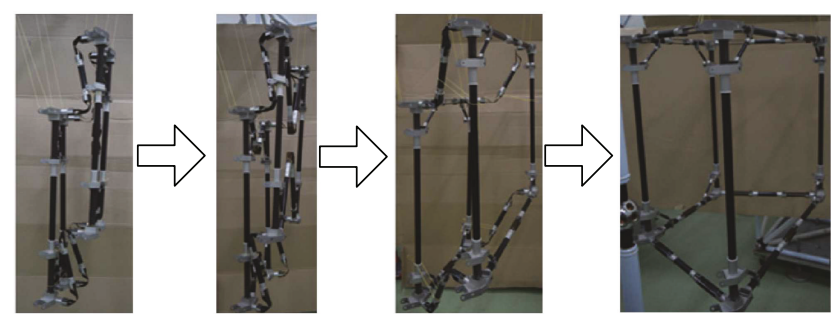

FIGURE 12: Expansion process of the double-layer unit mechanism.

The expansion function test of the double-layer unit is conducted, and the test process is shown in Figure 12. Figure 12 depicts that the inner and outer ring trusses are first deployed under the action of the elastic hinges. The link truss mechanism is then deployed. The entire development process is smooth, without interference, and getting stuck. Therefore, the expansion performance of the double-layer unit is good.

The modal testing system is composed of five parts, as shown in Figure 13.

The gravity compensation is conducted for the unit test by suspending the four corners on the combined microgravity compensation test bench with some flexible soft ropes. The acceleration of measured points is input into the modal analysis software through the multichannel vibration measurement and analysis system after the excitation is applied using the force hammer. This experiment needs four three-axis piezoelectric acceleration sensors made by PCB Piezotronics Inc. The acceleration response signals can be collected in the software Test. lab of LMS by knocking two times. The same test is repeated five times. We use the average results of five effective hammering to analyze the modal of the antenna unit.

Figure 14 provides the details of the vibration mode of the first two orders of the unit obtained using the three methods mentioned above. The vibration modes of the first two orders obtained by the three methods are consistent.

Table 5 shows the modal frequency of the first two orders of the unit.

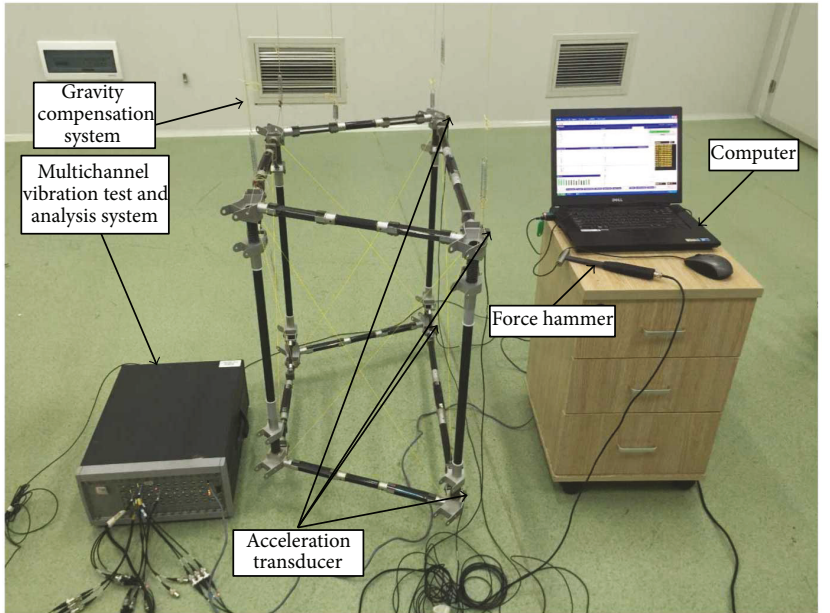

Figure 13: Modal test system.

In comparing the errors between the vibration frequency values obtained by the equivalent beam model and the finite element simulation, the fractional error $\Delta f$ is set as follows:

$$
\Delta f(\%)=\frac{\left|f_{i}^{e}-f_{i}^{o}\right|}{f_{i}^{o}} \times 100
$$

where $f_{i}^{e}$ and $f_{i}^{o}$ are the frequencies of the first $i$ order calculated by the equivalent model and finite element simulation.

Table 5 indicates that the fractional error of the first order of the equivalent model is $8.82 \%$ and the fractional error of the second order is $5.30 \%$. The fractional error is small, which proves the correctness of the equivalent model established in this study.

The values of the vibration frequency obtained by the equivalent beam model and finite element simulation are larger than those of the model test because the stiffness is weakened and the natural frequency is reduced by the assembly of the unit prototype and the clearance among the hinges.

6.2. Application of the Equivalent Model of a Double-Layer Hoop Antenna. As shown in Figure 15, a double-hoop antenna with a diameter of $20 \mathrm{~m}$ consisting of 24 units is set as an example to unify the research objects of the theoretical calculation, simulation, and experiment. Its equivalent model can be obtained by assembling several equivalent models established in Section 6.1 in the circumferential direction in accordance with the geometric topology of the original structure.

The equivalent model is calculated and analyzed by the finite element program, which considers the shear deformation and the anisotropy of the material. The finite element software ABAQUS was used in this paper. The simulation calculation is carried out by the finite element software, which is the same as in Section 6.1.

As shown in Table 6, the modal frequency of the first six orders of the antenna can be generated using the two methods mentioned above.

As described in Figure 16, the vibration modes of the first and fourth orders are torsion whereas the vibration modes of the second, third, fifth, and sixth orders are bending. The 


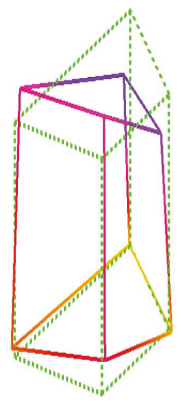

(a) Modal test (first order)

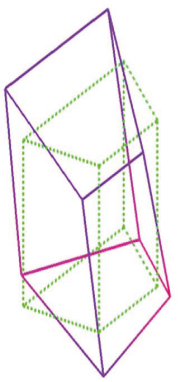

(d) Modal test (second order)

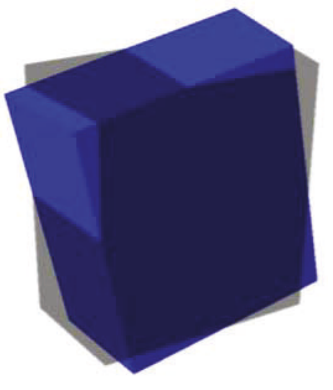

(b) Equivalent model (first order)

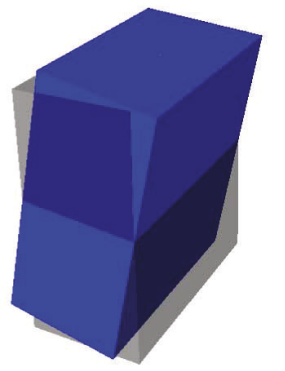

(e) Equivalent model (second order)

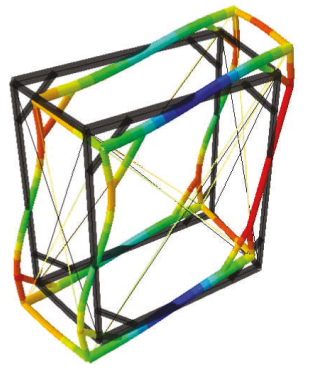

(c) Finite element (first order)

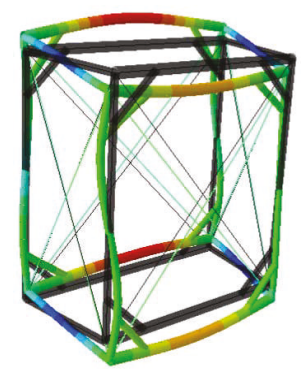

(f) Finite element (second order)

FIGURE 14: Vibration modes of the first two orders.

Table 5: Modal frequency of the unit (Hz).

\begin{tabular}{lccc}
\hline $\begin{array}{l}\text { Modal } \\
\text { order }\end{array}$ & $\begin{array}{c}\text { Equivalent } \\
\text { model }\end{array}$ & $\begin{array}{c}\text { Finite element } \\
\text { simulation }\end{array}$ & $\begin{array}{c}\text { Modal } \\
\text { test }\end{array}$ \\
\hline 1 & 43.358 & 47.454 & 40.113 \\
2 & 54.396 & 51.658 & 42.845 \\
\hline
\end{tabular}

TABLE 6: Modal frequency of the antenna.

\begin{tabular}{lccc}
\hline $\begin{array}{l}\text { Modal } \\
\text { order }\end{array}$ & $\begin{array}{c}\text { Frequency of } \\
\text { finite element } \\
\text { simulation (Hz) }\end{array}$ & $\begin{array}{c}\text { Frequency } \\
\text { of equivalent } \\
\text { model (Hz) }\end{array}$ & $\begin{array}{c}\text { Fractional } \\
\text { error (\%) }\end{array}$ \\
\hline 1 & 0.9508 & 0.9036 & 4.96 \\
2 & 0.9714 & 0.9516 & 2.04 \\
3 & 1.6852 & 1.6495 & 2.12 \\
4 & 2.5852 & 2.5363 & 1.89 \\
5 & 2.5227 & 2.4707 & 2.06 \\
6 & 3.3398 & 3.2717 & 2.04 \\
\hline
\end{tabular}

maximum fractional error of the modal frequency of the first six orders is $4.96 \%$. The vibration modes and the corresponding vibration frequencies of the antenna can be obtained by its equivalent model accurately.

The other modal frequency of the antenna with diameters of $50 \mathrm{~m}$ (100 units) and $100 \mathrm{~m}$ (200 units) is solved to verify the efficiency and accuracy of the equivalent model. The parameters of the equivalent model used in the 50 and $100 \mathrm{~m}$ diameter antennas are the same as that of the $20 \mathrm{~m}$ diameter antenna introduced above.

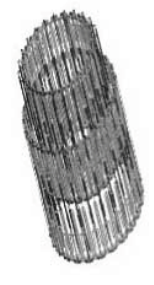

(a) Folded state

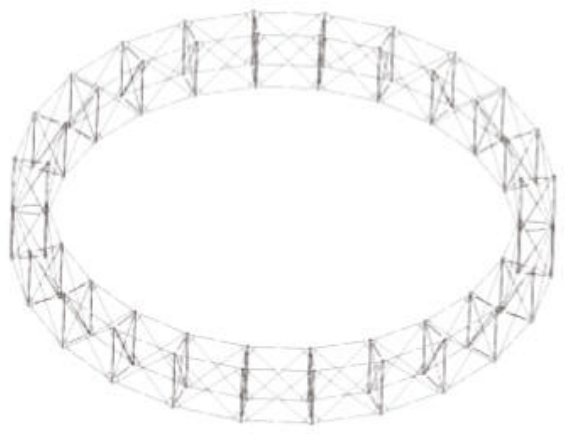

(b) Expanded state
FIGURE 15: Double-layer hoop antenna mechanism with a diameter of $20 \mathrm{~m}$.

The modal frequency and the time it takes are shown in Table 7.

Table 7 presents that the calculation results of the equivalent model and finite element simulation are similar. However, the equivalent model method has a great advantage in reducing calculation time. With the increase in the diameter, the advantage becomes obvious. Therefore, the use of the equivalent model can greatly reduce the calculation workload and results in high precision.

\section{Conclusion}

In this study, we construct deployable units driven by elastic hinges and a double-layer hoop deployable antenna composed of these units to realize the lightweight, high stiffness, 


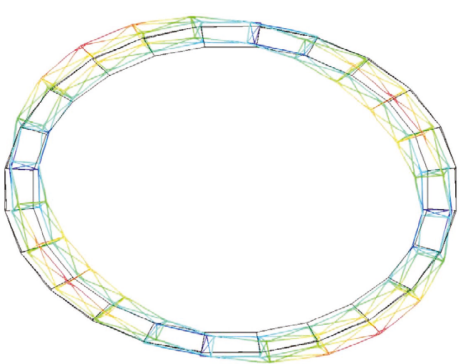

(a) The first order

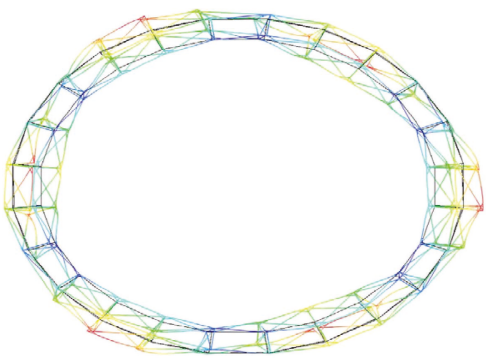

(d) The fourth order

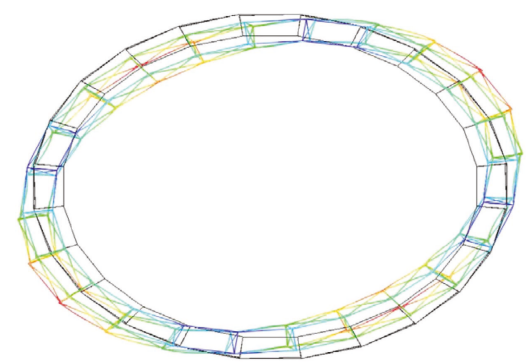

(b) The second order

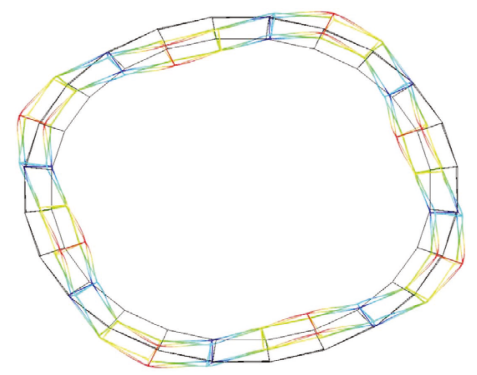

(e) The fifth order

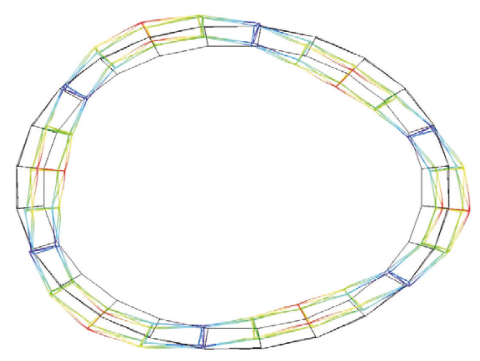

(c) The third order

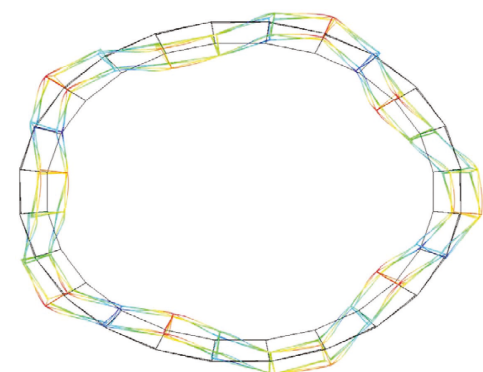

(f) The sixth order

FIGURE 16: Vibration modes of the double-layer hoop antenna.

TABLE 7: Calculation results obtained by two methods.

\begin{tabular}{lccccc}
\hline $\begin{array}{l}\text { Antenna } \\
\text { diameter }(\mathrm{m})\end{array}$ & $\begin{array}{c}\text { Frequency of equivalent } \\
\text { model (Hz) }\end{array}$ & $\begin{array}{c}\text { Frequency of finite element } \\
\text { simulation (Hz) }\end{array}$ & \begin{tabular}{c} 
Fractional error (\%) \\
\hline 20
\end{tabular} & $\begin{array}{c}\text { Time of equivalent } \\
\text { model (min) }\end{array}$ & $\begin{array}{c}\text { Time of finite element } \\
\text { simulation (min) }\end{array}$ \\
50 & 0.9036 & 0.9508 & 4.96 & 2.05 & 32.50 \\
100 & 0.005729 & 0.005564 & 2.97 & 4.25 & 72.55 \\
\end{tabular}

and passive driving design of large deployable antenna. We also propose a rational modeling method to develop an equivalent model of the double-layer hoop antenna. The equivalent beam models of the rods with an elastic hinge are established to facilitate the establishment of the equivalent model. The displacement of any point in the periodic unit is expressed through the displacement and strain components at the center of the periodic unit in accordance with the kinematical assumptions. The strain and kinetic energies in terms of nodal displacement, geometrical structure, and material parameters of the unit are derived. We analyze the stiffness and mass matrices of the equivalent beam model on the basis of energy equivalence principle. The equivalent models of the unit and the entire antenna are obtained. Theoretical calculation, finite element simulation, and modal test are conducted with the antenna to verify the equivalent model. Comparison of the theoretical values and the practical ones indicates that the analysis and simulation match the experiment to some degree, which confirms the accuracy of the equivalent model. The construction method of the equivalent model is significant for engineering practice applications because of its capability to realize a fast solution of the dynamic characteristics, the static characteristics, and the influence of various parameters of the large antenna. The equivalent method presented in this paper may serve as a reference in establishing other equivalent models of a large antenna composed of different units.

\section{Conflicts of Interest}

The authors declared no potential conflicts of interest with respect to the research, authorship, and/or publication of this article.

\section{Acknowledgments}

This project is supported by the joint funds of the National Natural Science Foundation of China (Grant no.U1637207, 51675114, and 51575119) and the College Discipline Innovation Wisdom Plan in China (Grant no. B07018).

\section{References}

[1] Z. Deng, H. Huang, B. Li, and R. Liu, "Synthesis of deployable/ foldable single loop mechanisms with revolute joints," Journal of Mechanisms and Robotics, vol. 3, no. 3, article 031006, 2011.

[2] L. Puig, A. Barton, and N. Rando, "A review on large deployable structures for astrophysics missions," Acta Astronautica, vol. 67, no. 1-2, pp. 12-26, 2010. 
[3] Z. You and Y. Chen, "Connectivity of Bennett linkages," in 43rd AIAA/ASME/ASCE/AHS/ASC Structures, Structural Dynamics, and Materials Conference, pp. 22-25, Denver, CO, USA, April 2002.

[4] Y. Chen and Z. You, "Mobile assemblies based on the Bennett linkage," Proceedings of the Royal Society A: Mathematical, Physical and Engineering Sciences, vol. 461, no. 2056, pp. 1229-1245, 2005.

[5] Y. Chen and Z. You, "On mobile assemblies of Bennett linkages," Proceedings of the Royal Society A: Mathematical, Physical and Engineering Sciences, vol. 464, no. 2093, pp. 12751293, 2008.

[6] S. Y. Liu and Y. Chen, "Myard linkage and its mobile assemblies," Mechanism and Machine Theory, vol. 44, no. 10, pp. 1950-1963, 2009.

[7] H. Huang, Z. Deng, and B. Li, "Mobile assemblies of large deployable mechanisms," Journal of Space Engineering, vol. 5, no. 1, pp. 1-14, 2012.

[8] S. Lu, D. Zlatanov, X. Ding, R. Molfino, and M. Zoppi, "Mechanisms with decoupled freedoms assembled from spatial deployable units," in Advances in Robot Kinematics, J. Lenarčič and O. Khatib, Eds., pp. 517-525, Springer, Cham, 2014.

[9] B. Li, X. Qi, H. Huang, and W. Xu, "Modeling and analysis of deployment dynamics for a novel ring mechanism," Acta Astronautica, vol. 120, pp. 59-74, 2016.

[10] A. Meguro, A. Tsujihata, N. Hamamoto, and M. Homma, "Technology status of the $13 \mathrm{~m}$ aperture deployment antenna reflectors for engineering test satellite VIII," Acta Astronautica, vol. 47, no. 2-9, pp. 147-152, 2000.

[11] F. Escrig, "Expandable space structures," International Journal of Space Structures, vol. 1, no. 2, pp. 79-91, 1985.

[12] L. Datashvili, "Foldability of hinged-rod systems applicable to deployable space structures," Ceas Space Journal, vol. 5, no. 3-4, pp. 157-168, 2013.

[13] L. Datashvili, S. Endler, B. Wei et al., "Study of mechanical architectures of large deployable space antenna apertures: from design to tests," Ceas Space Journal, vol. 5, no. 3-4, pp. 169-184, 2013.

[14] Z. You and S. Pellegrino, "Cable-stiffened pantographic deployable structures part 2: mesh reflector," AIAA Journal, vol. 35, no. 8, pp. 1348-1355, 1997.

[15] Y. Xu, F. Guan, X. Xu, H. Wang, and Y. Zheng, "Development of a novel double-ring deployable mesh antenna," International Journal of Antennas and Propagation, vol. 2012, Article ID 375463, 10 pages, 2012.

[16] M. Xia, Structure Design and the Accuracy Adjustment of the Profile of the Cable Net of the Double Ring Truss Antenna, Zhejiang University, Zhejiang, 2012.

[17] D. Lu, Dynamic Analysis and Optimization Design of Double Loop Deployable Truss Antenna, Zhejiang University, Zhejiang, 2014.

[18] X. Qi, H. Huang, Z. Miao, B. Li, and Z. Deng, "Design and mobility analysis of large deployable mechanisms based on plane-symmetric Bricard linkage," Journal of Mechanical Design, vol. 139, no. 2, article 022302, 2017.

[19] X. Qi, H. Huang, B. Li, and Z. Deng, "A large ring deployable mechanism for space satellite antenna," Aerospace Science and Technology, vol. 58, pp. 498-510, 2016.

[20] T. Li, "Deployment analysis and control of deployable space antenna," Aerospace Science and Technology, vol. 18, no. 1, pp. $42-47,2012$.
[21] M. A. Neto, J. A. C. Ambrosio, and R. P. Leal, "Composite materials in flexible multibody systems," Computer Methods in Applied Mechanics and Engine Loop, vol. 195, no. 50-51, pp. 6860-6873, 2006.

[22] Y. Zhang, B. Duan, and T. Li, "A controlled deployment method for flexible deployable space antennas," Acta Astronautica, vol. 81, no. 1, pp. 19-29, 2012.

[23] C. Shi, Design and Analysis of an Large Hoop Truss Deployable Antenna Mechanism [D], Harbin Institute of Technology, Heilongjiang, China, 2015.

[24] A. K. Noor, M. S. Anderson, and W. H. Greene, "Continuum models for beam and platelike lattice structures," AIAA Journal, vol. 16, no. 12, pp. 1219-1228, 1978.

[25] A. K. Noor and M. P. Nemeth, "Analysis of spatial beamlike lattices with rigid joints," Computer Methods in Applied Mechanics and Engineering, vol. 24, no. 1, pp. 35-59, 1980.

[26] A. K. Noor and W. C. Russell, "Anisotropic continuum models for beamlike lattice trusses," Computer Methods in Applied Mechanics and Engineering, vol. 57, no. 3, pp. 257277, 1986.

[27] A. K. Noor, "Continuum modeling for repetitive lattice structures," Applied Mechanics Reviews, vol. 41, no. 7, pp. 285-296, 1988.

[28] A. Salehian and D. J. Inman, "Dynamic analysis of a lattice structure by homogenization: experimental validation," Journal of Sound and Vibration, vol. 316, no. 1-5, pp. 180$197,2008$.

[29] A. Salehian and D. J. Inman, "Micropolar continuous modeling and frequency response validation of a lattice structure," Journal of Vibration and Acoustics, vol. 132, no. 1, article 011010, p. 7, 2010.

[30] O. Bruls, P. Duysinx, and J. C. Golinval, "The global modal parameterization for non-linear model-order reduction in flexible multibody dynamics," International Journal for Numerical Methods in Engineering, vol. 69, no. 5, pp. 948-977, 2007.

[31] F. Naets, G. H. K. Heirman, D. Vandepitte, and W. Desmet, "Inertial force term approximations for the use of global modal parameterization for planar mechanisms," International Journal for Numerical Methods in Engineering, vol. 85, no. 4, pp. 518-536, 2011.

[32] F. Naets, G. H. K. Heirman, and W. Desmet, "Subsystem global modal parameterization for efficient simulation of flexible multibody systems," International Journal for Numerical Methods in Engineering, vol. 89, no. 10, pp. 1227-1248, 2012.

[33] F. Naets, T. Tamarozzi, G. H. K. Heirman, and W. Desmet, "Real-time flexible multibody simulation with global modal parameterization," Multibody System Dynamics, vol. 27, no. 3, pp. 267-284, 2012.

[34] F. Liu, D. Jin, and H. Chen, "An equivalent mechanics model for dynamic analysis of hoop truss structures," Journal of Vibration Engineering, vol. 26, no. 4, pp. 516-521, 2013.

[35] F. Liu, D. Jin, and H. Wen, "Equivalent dynamic model for hoop truss structure composed of planar repeating elements," AIAA Journal, vol. 55, no. 3, pp. 1058-1063, 2017.

[36] F. Liu and D. Jin, "Equivalent circular ring model for the radial vibration analysis of hoop truss structures," Chinese Journal of Theoretical and Applied Mechanics, vol. 48, no. 5, 2016.

[37] F. Liu and D. Jin, "Analytical investigation of dynamics of inflatable parabolic membrane reflector," Journal of Spacecraft and Rockets, vol. 52, no. 1, pp. 285-294, 2015. 
[38] F. S. Liu, Dynamic Equivalent Modeling and Vibration Control of Large Space Structures, Nanjing University of Aeronautics and Astronautics, Nanjing, China, 2015.

[39] H. Yang, R. Liu, Y. Wang, Z. Deng, and H. Guo, "Experiment and multiobjective optimization design of tape-spring hinges," Structural and Multidisciplinary Optimization, vol. 51, no. 6, pp. 1-12, 2015.

[40] J. D. Renton, Elastic Beams and Frames, Horwood Publishing Series: Engineering Science, Horwood Publishing, Ltd., International Publishers, Coll House, Westergate, Chicester, West Sussex, UK, 2nd edition, 2002. 


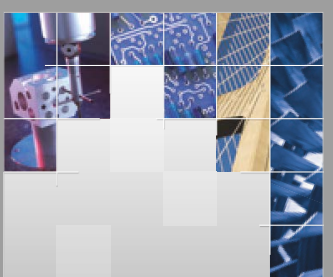

\section{Enfincering}
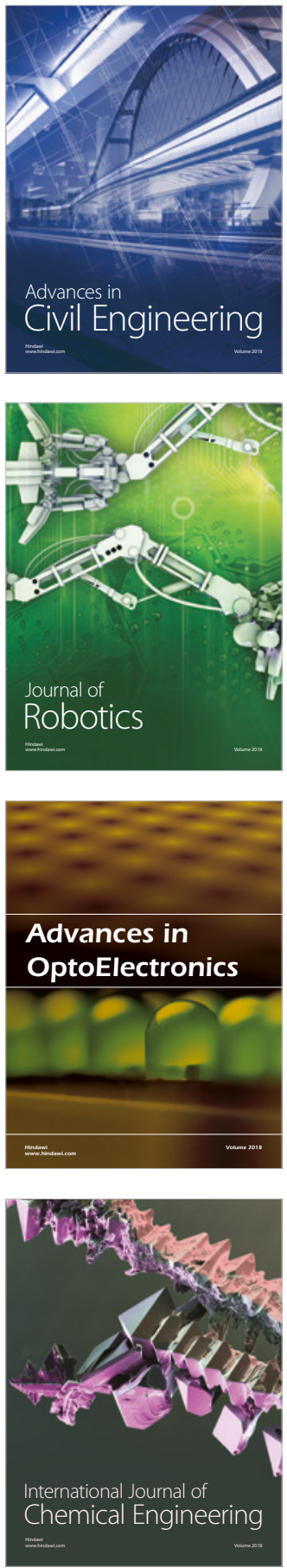

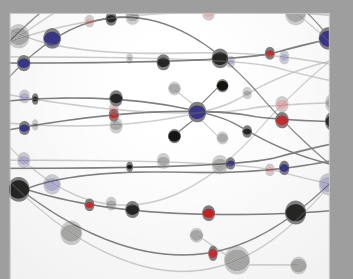

\section{Rotating \\ Machinery}

The Scientific World Journal

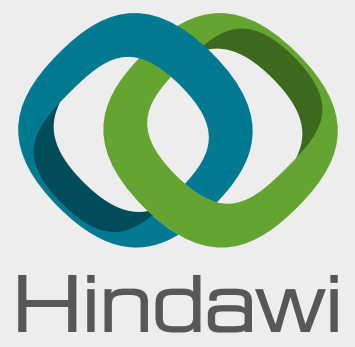

Submit your manuscripts at

www.hindawi.com
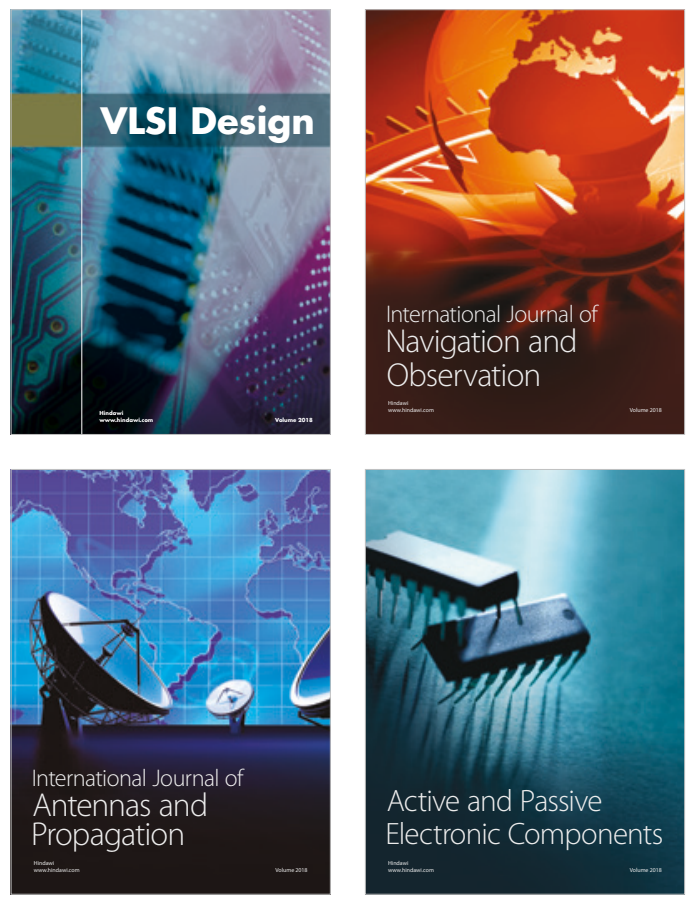
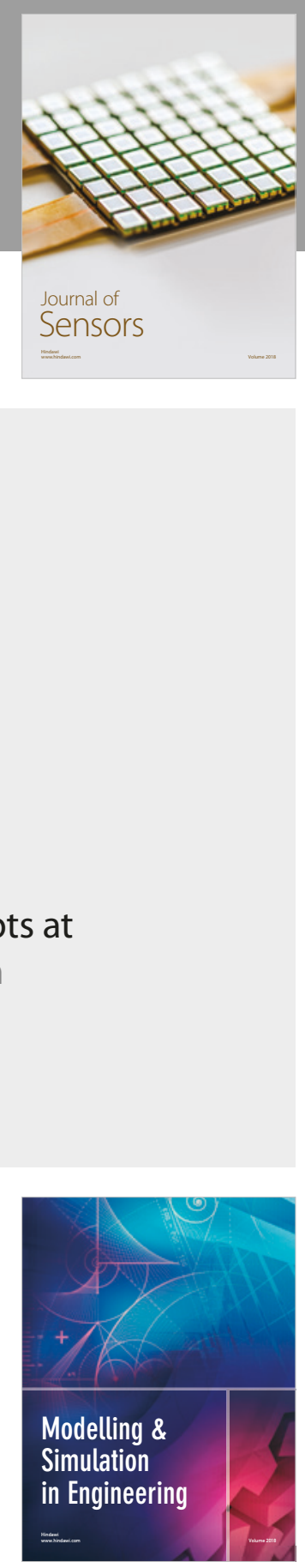

\section{Advances \\ Multimedia}
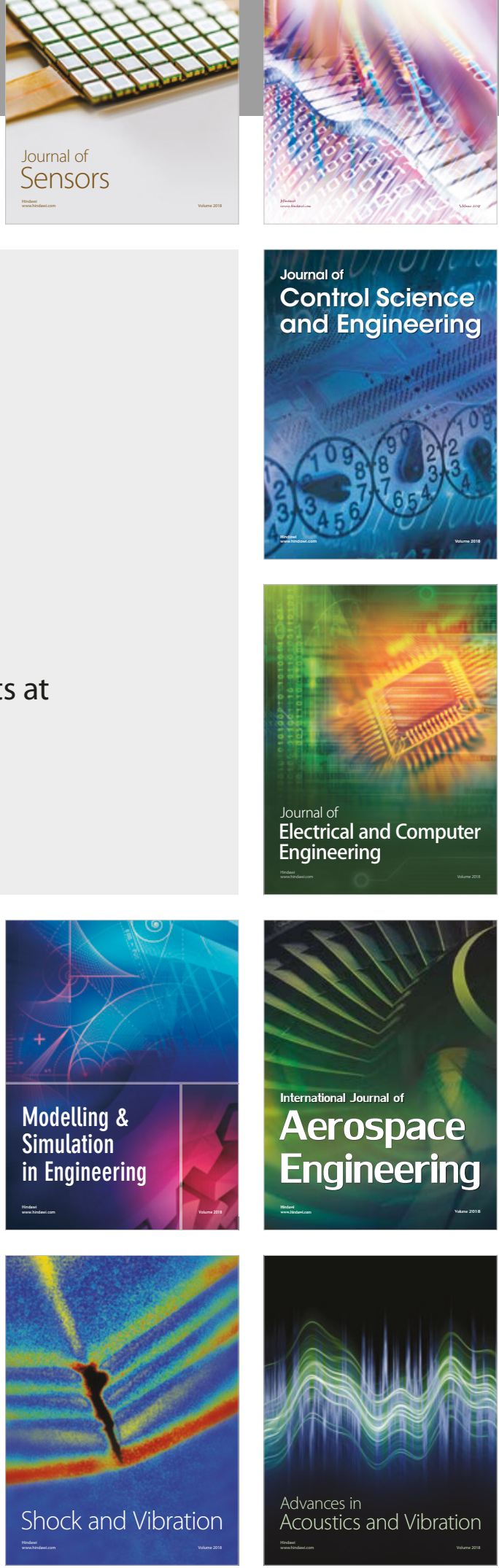